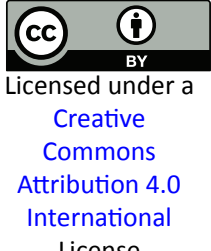

License

\title{
Vowel harmony decay in Old Norwegian
}

\author{
JADE J. SANDSTEDT \\ UiT The Arctic University of Norway
}

\begin{abstract}
Vowel harmony involves the systematic correspondence between vowels in some domain for some phonological feature. Though harmony represents one of the most natural and diachronically robust phonological phenomena that occurs in human language, how and why harmony systems emerge and decay over time remains unclear. Specifically, what motivates harmony decay and the pathways by which harmony languages lose harmony remains poorly understood since no consistent historical record in any single language has yet been identified which displays the full progression of this rare sound change (McCollum 2015, 2020; Kavitskaya 2013, Bobaljik 2018). In this paper, I explore the progression and causation of vowel harmony decay in Old Norwegian (c 1100-1350). Using a graphophonologically tagged database of a sample of 13 th- to 14th-century manuscripts, I present novel corpus methods for tracking and visualising changes to vowel co-occurrence patterns in historical records, demonstrating that the Old Norwegian corpus provides a consistent and coherent record of harmony decay. The corpus distinguishes categorical pre-decay harmony, probabilistic intermediate stages, and post-decay non-harmony. Across the Old Norwegian manuscripts, we observe a variety of pathways of harmony decay, including increasing harmony variability via the collapse of harmony classes introduced by vowel mergers, the lexicalisation of historically harmonising morphemes, and trisyllabic vowel reductions which limit harmony iterativity. This paper provides the first detailed corpus study of the full spectrum and causation of this rare sound change in progress and provides valuable empirical diagnostics for identifying and analysing harmony change in contemporary languages.
\end{abstract}

\section{Introduction}

\subsection{Vowel harmony and harmony decay}

This paper explores the causes and progression of a rarely attested sound change: vowel harmony decay or the loss of vowel harmony. Very 
generally defined, vowel harmony is a process in which vowels in a word show systematic correspondence for some feature. A typical example is provided in (1) illustrating perseveratory labial harmony in Yakut (Siberian-Turkic). In Yakut, non-initial vowels must assimilate to rootinitial vowels for rounding, resulting in round/non-round [e i a u] - [ø y o u] alternations on suffixes (Anderson 1998, Krueger 1962). Throughout this paper I colour-code the data to highlight contrasting harmony classes and underline harmony triggers or feature-donors, as illustrated by rootinitial vowels in (1).

(1) Rounding harmony in Yakut
a. kel-el-ler 'come'-3.PRES.-PL.
b. kør-øl-lør 'see'-3.PRES.-PL.
c. kele-yin 'come'-2.SG.
d. døjø-zyn 'grow quiet'-2.sG.

Vowel harmony like that in (1) is considered to be one of the most natural phenomena that occurs in human language. Being a type of assimilation, harmony systems ease articulation, make speech perception more predictable, and may serve to strengthen perceptually weak cues where harmony spreads from weak to strong positions - e.g. from unstressed/non-initial to stressed/root-initial positions (Suomi 1983, Gallagher 2010, Walker 2005). Acquisitional research suggests that harmony patterns are easy to learn and mastered early, with language learners showing few to no harmony violations by about the age of 2;6 (MacWhinney 1978, Leiwo, Kulju \& Aoyama 2002, Altan 2007). In addition to harmony processes' potential functional motivations and acquisitional ease, vowel harmony is typologically very common and is one of the most historically stable processes that occur in phonology, as illustrated by remarkably long-lasting harmony systems such as millennia-old backness/tongue root harmony in Altaic and Uralic language families (Poppe 1960; Vaux 2009; Harrison, Dras \& Kapicioglu 2006; Binnick 1991; Janhunen 1982). All things considered, it seems that once a language has developed vowel harmony, it is very difficult to lose it.

Despite the stability of harmony systems, diachronic and/or crossdialectal correspondences with historical and existing harmony languages show that harmony systems do decay. For instance, in contrast to modern-day Turkish which displays backness harmony in (2a), the related South Eastern Turkic language Uzbek in (2b) has lost vowel harmony, as illustrated by the lack of front/back [a e] suffixal alternations (Csató \& Johanson 1998; Sjoberg 1963). This raises a crucial historical 
phonological question: if harmony is so natural and historically stable, what motivates harmony decay and how do harmony processes die?

(2) Turkic backness harmony lost in Uzbek

\begin{tabular}{|c|c|c|c|c|c|c|}
\hline BACK & $\begin{array}{l}\text { dóst-lar } \\
\text { kul-lar }\end{array}$ & & $\begin{array}{l}\text { 'friend'-PL. } \\
\text { 'slave'-PL. }\end{array}$ & $\begin{array}{l}\text { dóst-lar } \\
\text { qul-lar }\end{array}$ & & $\begin{array}{l}\text { 'friend'-PL. } \\
\text { 'slave'-PL. }\end{array}$ \\
\hline ONI 1 & $\begin{array}{l}\text { et-ler } \\
\text { diss-ler }\end{array}$ & $\begin{array}{l}{ }^{*} \text { et-lar } \\
*_{\text {diș-lar }}\end{array}$ & $\begin{array}{l}\text { 'meat'-PL. } \\
\text { 'tooth'-PL. }\end{array}$ & $\begin{array}{l}\text { et-lar } \\
\text { tish-lar }\end{array}$ & $\begin{array}{l}{ }^{*} \text { et-ler } \\
*_{\text {tish-ler }}\end{array}$ & $\begin{array}{l}\text { 'meat'-PL. } \\
\text { 'tooth'-PL. }\end{array}$ \\
\hline
\end{tabular}
(a) Turkish - [-lar] / [-ler]
(b) Uzbek - [-lar]

We currently know little for certain about the causes and nature of harmony decay since we have considerably limited diachronic sources of evidence for this sound change. As far as I am aware, no historical record is yet digitally readily accessible for large-scale corpus linguistic research which demonstrates the full progression of harmony decay in detail from beginning to end: i.e. from pre-decay, robust harmony to post-decay nonharmony. Thus far, harmony decay has been investigated using comparisons between harmonic/non-harmonic dialects, such as varying stages of harmony decay attested in Crimean Tatar (Turkic; Kavitskaya 2013). For certain languages, we have limited diachronic comparisons, such as harmony changes between the extinct Turkic language Chaghatai (Bodrogligeti 2002, Eckmann 1966) and its descendant Uzbek (Sjoberg 1963; Harrison, Dras \& Kapicioglu 2006). Finally, agent-based computational modelling has been used to explore various potential trajectories of vowel harmony evolution and decay (e.g. Harrison, Dras \& Kapicioglu 2006; Mailhot 2010). From this work, the primary suspected causes of harmony decay include changes in vowel inventories (mergers/splits), the loss of harmonising morphology, and language contact - i.e. via the influence of divergent phonological and grammatical structures in prolonged periods of bilingualism (McCollum 2020). Despite the considerable scope of harmony decay research, we still lack significant empirical evidence with which to investigate these factors in detail. There is a crucial missing link in the historical typological record: the full detailed transition from a harmonic to non-harmonic language. It therefore remains unclear in practice exactly how and why these factors might converge on the loss of harmony.

\subsection{Old Norwegian height harmony and harmony decay}

In this paper, I present a novel case of vowel harmony decay in Old Norwegian based on a database of vowel patterns collected from twelve 
scribes in eleven recently digitised 13th- and 14th-century manuscripts. This corpus provides the beginnings of a much more detailed picture of harmony decay than has previously been made available for other harmony decaying languages.

As illustrated below in (3), Old Norwegian (c 1100-1350) displays a form of vowel height harmony via vowel lowering, spreading from stressed (root-initial) to unstressed syllables, resulting in [i u] and [e o] suffixal alternations. In the Old Norwegian data in this paper, I provide interpreted phonetic and phonological forms alongside the elicited orthographic representations from the manuscripts, which are provided in angled brackets. ${ }^{1}$

(3) Height harmony in Old Norwegian

\begin{tabular}{|c|c|c|c|c|c|}
\hline & $\begin{array}{l}\text { hurss-i } \\
\text { skip }-i\end{array}$ & $\begin{array}{l}<\mathrm{h} \\
<\mathrm{fk}\end{array}$ & -um & is $>$ & $\begin{array}{l}. / \text { PL. } \\
\text { PL. }\end{array}$ \\
\hline & & & & $<$ feglō $>$ & il'-DAT.SG./ \\
\hline
\end{tabular}

The basic pre-decay harmony patterns in (3) are well evidenced, being documented in a wide range of manuscript, charter, and runic material both in central dialects of Old Norwegian as well as Old Swedish (Hødnebø 1977, Kock 1882). A sample of Old Norwegian text from the manuscript AM 619 4to is provided in Figure 2. ${ }^{2}$ Similar height harmony patterns are sporadically attested in Norse material farther afield; for instance, in Scanian law codices (Frederiksen 2018: 153-55), Orcadian charters and runic inscriptions (Flom 1934b, Barnes 1994), as well as Greenlandic runic material (Sandstedt 2018: §4.1; Imer 2017). Lastly, while no Icelandic material displays robust and consistent harmony like (3), Flom (1934a) has identified statistical tendencies towards height harmonic distributions in certain Old Icelandic manuscript fragments, which may indicate intermediary or post-harmony decay remnants in Old Icelandic. On the whole it seems therefore that height harmony may

\footnotetext{
${ }^{1}$ The Old Norwegian harmony data in this paper, unless otherwise specified, are collected from the following pre-decay harmony manuscripts: The Legendary Saga of St. Olaf (De la Gardie 8 fol, 70v-110v - c 1225-50) and The Saga of Barlaam and Josephat (Holm perg 6 fol - $c$ 1275). See Sandstedt (2018: §4.3) for philological and codicological details. ${ }^{2}$ Facsimiles and philological details for AM 619 4to are available online at: https: //handrit.is/is/manuscript/view/en/AM04-0619. A diplomatic transcription is available in the Medieval Nordic Text Archive: https://www.menota.org/forside. xhtml.
} 
well have been a much more widespread feature of the Nordic languages prior to parchment written records. ${ }^{3}$ Height harmony was ultimately lost across all Nordic languages. According to traditional philological descriptions, Old Norwegian vowel harmony decayed gradually over the course of the 13th to 14 th centuries, as evidenced by the decreasing frequency and increasing variability of harmonic spelling patterns (Hødnebø 1977, Flom 1934b, Seip 1955, Hagland 1978).

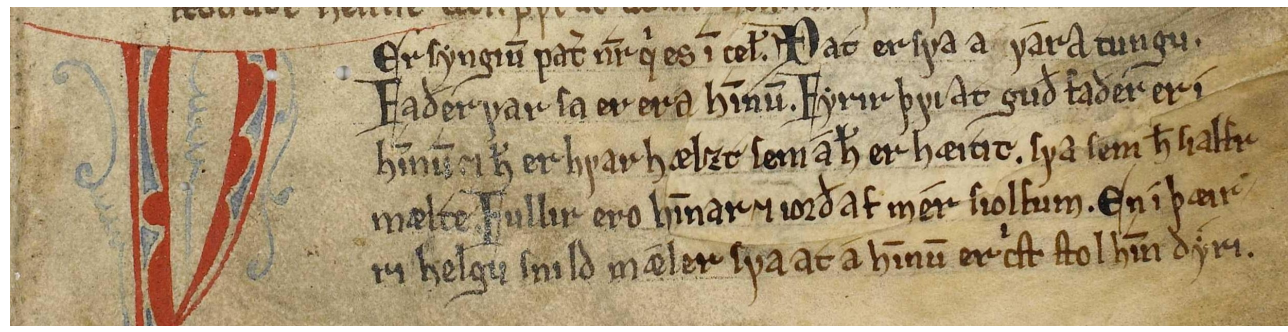

Figure 2: The Old Norwegian homily book. AM 619 4to, c 1200-25, the Arnamagnæan Institute, University of Copenhagen. Image by Suzanne Reitz. Fol. 76r, lines 26-30.

VEr fyngium pater noster qui es in celis. Đat er fva a vára tungu. / Faðer var fa er er a himnum. Fyrir pvi at guð faðer er í / himnum. ok hann er hvar hælzt fem á hann er hæitit. fva fem hann fialfr / mælte. Fullir ero himnar ok iorð af mér fiolfum. En í pæir · ri helgu fnild mǽler fva at á himnum er Crift ftol hinn dýri. ['We sing pater noster qui es in cælis. It is so in our language: / Our father that which is in heaven. For God, father, is in heaven, and he is everywhere where he is called, as he himself said: "Full are heaven and earth of me myself." And in the holy text it is thus said that in heaven is Christ's precious footstool.']

No detailed study of the progression or causation of Old Norwegian harmony decay has yet been undertaken, and the philological nature of the Old Norwegian corpus poses significant methodological challenges for eliciting reliable phonological data. In recent decades, however, a sizeable portion of 13th- and 14th-century manuscripts has been digitised in a form suitable for large-scale corpus linguistic research in the Medieval Nordic Text Archive (MENOTA; http: //menota.org/) and Paulsen's (2017) emRoon database (http://www. emroon.no/). Expanding on the

\footnotetext{
3 Though there is runic material which pre-dates writing on parchment, Viking-Age runic orthography fails to distinguish many phonological contrasts - including high vs. mid vowel qualities. For instance, the runes \langle|$\Lambda>$ represent both [i e] and [u o] vowels, respectively, such that a Viking-Age form such as $\uparrow \wedge \uparrow \mathbb{R}$ tutir 'daughter' could represent either height-harmonic [do:tter] or disharmonic [do:ttir] pronunciations. Given this ambiguity, Viking-Age inscriptions provide no viable harmony data, and we know relatively little about the evolution of height harmony in the Nordic languages.
} 
methods developed by Sandstedt (2018), I provide a database of 275,554 words with etymologically and linguistically annotated vowel patterns from twelve scribes in eleven 13th- to 14th-century manuscripts, which provides a sufficient foundation for an exploratory study of Old Norwegian harmony patterns. This corpus displays a clear trajectory of harmony decay with coherent sub-groupings in the data, distinguishing 1) rule-governed, pre-decay harmony, 2) probabilistic, inconsistent intermediary systems, and 3) lexicalised, post-decay non-harmony.

This is the first corpus that provides a detailed spectrum of harmony decay across a diverse historical record, making Old Norwegian typologically a very significant specimen for identifying and studying harmony systems in the course of change. In section 2 I outline this study's corpus methods and the structure of the Old Norwegian harmony database. I demonstrate some novel methods for tracking and visualising vowel harmony changes in written corpora in section 3. Finally, I track the pathways and causation of harmony decay in this corpus in detail in section 4. This study identifies increasing harmony variability via the collapse of harmony classes introduced by vowel mergers, the lexicalisation of historically harmonising morphemes, and trisyllabic vowel reductions. An overall summary of the study and its results are given in section 5 .

\section{The Old Norwegian corpus}

Old Norwegian from $c$ 1100-1350 displays varying degrees of height harmony (Sandstedt 2017, 2018; Myrvoll 2014; Hødnebø 1977), but generalising reliable phonological data on the basis of medieval philological material like that in Figure 2 is obviously very challenging. Using rich linguistic annotations in the MENOTA and emROoN corpora , I have automated the collection, clean-up, and further linguistic annotation of vowel patterns from Old Norwegian manuscripts.

\subsection{Data collection and annotation methods}

The MENOTA and emROON corpora provide an increasing sample of digitised Old Norwegian manuscript transcriptions. This study's elicited corpus comprises eleven manuscripts written by twelve scribes, as outlined below in Table 1 . To ensure an accurate and viable data-set, this sample includes only sources which are lexically and morphologically tagged. All the manuscripts are estimated to have been produced between the mid13th and mid-14th centuries, but their exact relative chronology remains unclear. After non-Norse material and heavily abbreviated forms have 
been removed, this corpus provides a sample of 338,640 words. With the help of Pavel Iosad, I have written scripts to automate the collection, clean up, and annotation of Old Norwegian vowel patterns from MENOTA-style XML-transcriptions.

\begin{tabular}{|c|c|c|c|c|c|c|}
\hline Abbr. & Signature & MS or work title & & Date & Provenance & Words \\
\hline AM619 & AM 6194 to & The Norwegian Homily Book & $c$ & $1200-25$ & Bergen & 60729 \\
\hline Pamph & De la Gardie $4-7$, fols. $3 r-5 v$ & Pamphilus saga & $c$ & 1270 & Bergen & 4470 \\
\hline Streng_h1 & De la Gardie $4-7$, fols. $17 v a 6-29 v$ & Strengleikar-hand 1 & $c$ & 1270 & Bergen & 18341 \\
\hline Streng_h2 & De la Gardie $4-7$, fols. $30 r-43 v$ & Strengleikar-hand 2 & $c$ & 1270 & Bergen & 20111 \\
\hline AM243 & AM $243 \mathrm{~b} \alpha$ fol & King's Mirror & $c$ & 1275 & Bergen & 63910 \\
\hline H34 & Holm perg 34 4to & $\begin{array}{l}\text { Bójarlog ok Farmannalog } \\
\text { Magnúss Hákonarsónar }\end{array}$ & $c$ & $1275-1300$ & Bergen & 56509 \\
\hline H6 & Holm perg 6 fol & Saga of Barlaam and Josaphat & $c$ & 1275 & Eastern & 76411 \\
\hline DG8 & De la Gardie 8 fol, fols. $70 v-110 v$ & Legendary saga of St. Olaf & $c$ & $1225-50$ & Trøndsk & 41142 \\
\hline H4_h1 & Holm perg 4 fol, fols. $1 \mathrm{r}-14 \mathrm{v}$ & piðriks saga af Bern-hand1 & $c$ & $1275-1300$ & Trøndsk & 8281 \\
\hline NRA58c & NRA $58 \mathrm{C}$ & A fragment of Konungs skuggsjá & $c$ & $1260-70$ & Uncertain & 2992 \\
\hline H17 & Holm perg 17 4to & Saga of Archbishop Thómas & $c$ & 1300 & Uncertain & 59756 \\
\hline NRA7 & NRA 7 & $\begin{array}{l}\text { A fragment of Landslog } \\
\text { Magnúss Hákonarsonar }\end{array}$ & $c$ & $1300-50$ & Uncertain & 5720 \\
\hline
\end{tabular}

Table 1: The elicited manuscripts' size, estimated date, and estimated provenance

I have organised the vowel patterns in this corpus into individual pairwise sequences (seq_no), which are then evaluated for height agreement (i.e. $V H=$ TRUE if $V 1 \_h i g h=V 2_{-}$high, else FALSE). This is illustrated below in Table 2 for the quadsyllabic word [hofðingj-a-n-om] <hofðíngianom> 'chieftain'-DAT.SG.-DEF.-DAT.M.SG. Note that medieval spelling patterns may display considerable variation, not all of which is linguistically relevant; cf. e.g. non-unique [o 5$]-<0>$ or [i j]-<i> spellings in <hofðíngianom $>$ for [həfðingjanom] in Table 2. Extra-linguistic orthographic variation of this kind can significantly complicate phonological corpus studies. To control for such issues, the data collection algorithm avoids consonantal spellings (e.g. $<i \mathrm{u}>$ for $[j \mathrm{v}]$ ), and I have written scripts which clean up and augment the elicited orthographic patterns with additional etymological and phonological annotations for the 600 most common lexemes in the corpus. These annotations include etymological or interpreted phonetic sound values for each vowel (Etym1/Etym2 in Table 2) which are defined according to the semi-normalised Old Norse representations in Holthausen's (1948) comparative and etymological Old West Norse dictionary. The data are further annotated for vowel height class, backness, length, stress, phonetic environment, simplex/compound status, and a range of other linguistic variables; see Sandstedt (2018: ch. 4) for a more detailed presentation of these corpus methods. Using this comparative grapho-phonological approach, we can distinguish potentially competing 
linguistic, etymological, and orthographic influences on surface spelling patterns in Old Norwegian manuscripts and analyse harmony patterns in relationship to a wide variety of linguistic and orthographic factors.

\begin{tabular}{|c|c|c|c|c|c|c|c|c|}
\hline Harmonic span & seq_no & V1 & V2 & Etym1 & Etym2 & V1_high & V2_high & VH \\
\hline \{hofðíng\} ianom & 1 & $<0>$ & $<i ́ \mid>$ & J & i & False & True & False \\
\hline hof $\{$ ðíngia $\}$ nom & 2 & $<i ́>$ & $<a>$ & $\mathrm{i}$ & $\mathrm{a}$ & True & False & False \\
\hline hofð̋ing \{ianom\} & 3 & $<\mathrm{a}>$ & $<0>$ & $\mathrm{a}$ & o & False & False & True \\
\hline
\end{tabular}

Table 2: Division into pairwise vowel sequences

The sub-set of the database with linguistic annotations captures $81.4 \%$ of the original data $(275,554 / 338,640)$, providing us with a total of 289,070 individual vowel sequences from twelve individual writers. Given this corpus study's heavy use of etymological and linguistic annotations, this database allows for a detailed investigation of Old Norwegian vowel patterns and their variation.

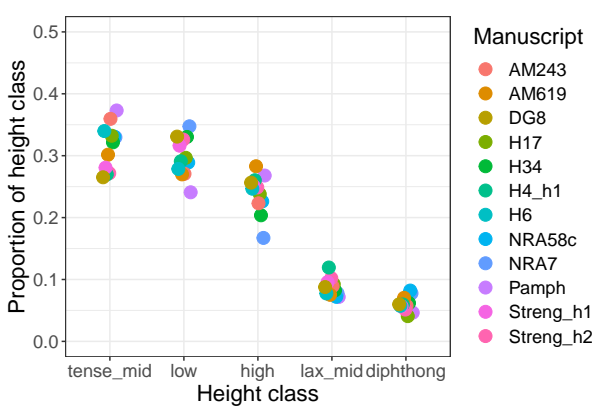

(a) Vowel height class proportional frequencies

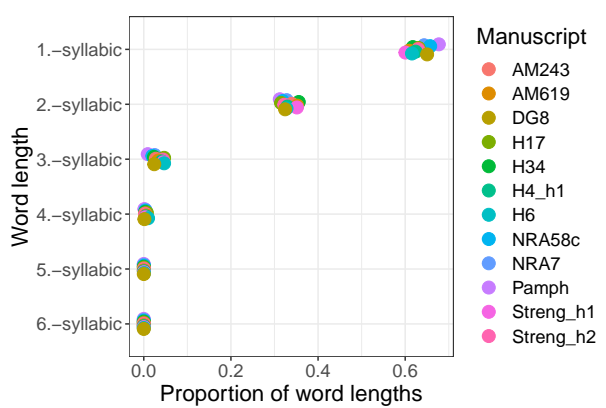

(b) Word length proportional frequencies

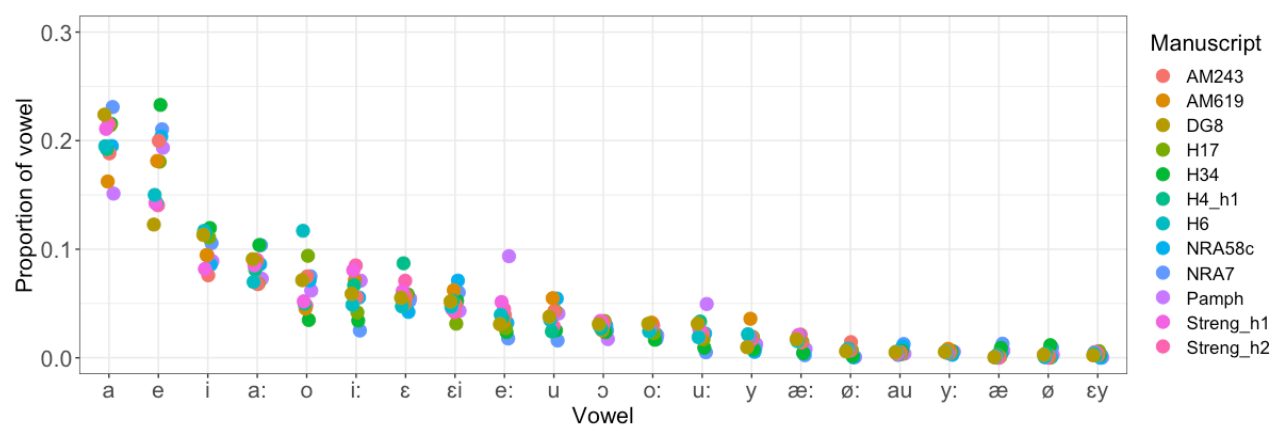

(c) Stressed vowel proportional frequencies

Figure 3: Consistent vowel, height class, and word length frequencies across manuscripts 
A look at some descriptive statistics suggests that the manuscripts provide consistent and coherent natural language data. Old Norwegian is a moderately synthetic language, similar to German, and the average Old Norwegian word is considerably short, with only 1.53 mean number of syllables and a median word length in writing of 4 letters. The average proportion of vowels to word length in writing is approximately $43 \%(1.64 / 3.95)$, and around $40 \%$ of words are polysyllabic, which can provide vowel harmony insights. Figure 3 illustrates reasonably good agreement across the manuscripts on vowel, word length, and vowel height class frequencies, suggesting the corpus provides reliable data for phonological analysis.

\subsection{Vowel harmony descriptive generalisations}

The Old Norwegian sound inventory and chief orthographic correspondences evidenced in this corpus are provided in Table 3 (cf. Sandstedt 2017: §2.2, 2018: §5.1). Old Norwegian additionally displays three diph-

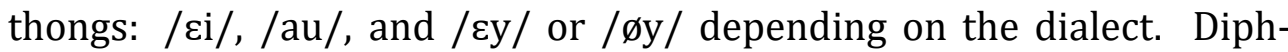
thongs trigger [+high] harmony like high vowels: e.g. [le्tit-i] <læiti> 'seek'-PRES.3.SG.SUBJ. like [liv-i] <lifi> 'live'-PRES.3.SG.SUBJ. Because of the considerably large vowel inventory in Old Norwegian, not all vowel phones have unique letter correspondences in writing, distinguishing 10 vowel qualities with only 8 contrastive vowel graphemes. Specifically, [ $\varepsilon$ ग] or normalised Old Norse short $æ-Q$ are represented variably by mid $<$ e o> and low <æ a> vowel letters; e.g. DG8 [həfði] < hofði, hafði> 'head'DAT.SG. and [sett] <sætt, sett> 'set'-PRET.PART.NOM.N.SG.

\begin{tabular}{|c|c|c|c|c|c|c|}
\hline$[\mathrm{i}, \mathrm{i}:]$ & $<\mathrm{i}>$ & {$[\mathrm{y}, \mathrm{y:}]$} & $<y>$ & {$[\mathrm{u}, \mathrm{u}:]$} & $<\mathrm{u}>$ & $\mathrm{HIGH}$ \\
\hline$[\mathrm{e}, \mathrm{e}$ & $<e>$ & {$[\varnothing, \varnothing:]$} & $<œ, \emptyset>$ & {$[0,0:]$} & $<0>$ & Mid TEnse \\
\hline$[\varepsilon]$ & $<æ, \mathrm{e}>$ & & & [э] & $<0, a>$ & MID LAX \\
\hline æ, æ:] & $<æ>$ & & & {$[a, a:]$} & $<a>$ & Low \\
\hline
\end{tabular}

Table 3: Old Norwegian sound-letter correspondences

As summarised earlier in section 1.2, pre-decay Old Norwegian manuscripts feature height harmony via vowel lowering, spreading from stressed (root-initial) to unstressed syllables. This results in unstressed $\mathrm{mid} /$ high alternations on suffixes, as illustrated below by dative inflections /-i, -um/ in (4), repeated from (3). 
(4) Height harmony in Old Norwegian

\begin{tabular}{|c|c|c|c|c|c|}
\hline & $\begin{array}{l}\text { huss-i } \\
\text { skip-i }\end{array}$ & $\begin{array}{l}<\text { hufi> } \\
\text { < fkipi> }\end{array}$ & 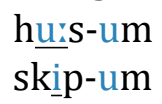 & $\begin{array}{l}<\text { hufū> } \\
<\text { fkipum> }\end{array}$ & $\begin{array}{l}\text { X. PL. } \\
\text { PL. }\end{array}$ \\
\hline & & & & & \\
\hline
\end{tabular}

In addition to the high/mid alternations in (4), Old Norwegian displays two classes of neutral segments - vowels which fail to undergo harmony alternations in harmony target/recipient positions: harmonic blocking /æ: a a: $/{ }^{4}$ and neutral blocking / $\varepsilon$ J/. As illustrated by /a a:/harmony patterns below in (5), Old Norwegian harmonic blocking vowels trigger harmonic lowering like other non-high vowels in stressed/trigger positions (5ab). Though Old Norwegian low vowels can trigger harmony, they are unpaired for the harmony feature and fail to undergo alternations in target positions, resulting in harmonically blocked high-harmony in (5cd). Old Norwegian low vowels are thus both phonologically active lowering triggers and visible blockers of height harmony. Low vowels initiate their own harmonic span regardless of position and can only be followed by non-high [e o] unstressed vowels. This form of harmonic blocking is attested in a variety of other height harmony languages; cf. e.g. Mbunda (K.15; aka Chimbunda, Kimbunda, or Mbuunda; Gowlett 1970), spoken in Angola and Zambia, which displays height harmony via vowel lowering with harmonic blocking low vowels.

(5) Harmonic blocking low /a, a:/ vowels
a. /all-ri/ $\rightarrow$ [all-re] <allre $>$
b. /vaind-ri/ $\rightarrow$ [vaind-re] <vanndre $>$
'all'-DAT.F.SG.
c. /likk-ar-i/ $\rightarrow$ [likk-ar-e] <likare>
'bad'-DAT.F.SG.
d. /rifn-að-i/ $\rightarrow$ [rifn-að-e] $<$ rifnaðe $>$
'likely'-COMP-NOM.SG.
'crack'-PRET.-3.SG.

Old Norwegian displays a second class of neutral segments: neutral blocking, lax mid / $\varepsilon$ J/ vowels (normalised Old Norse short 2 and $q$ ). As demonstrated by the vowel patterns in (6), lax mid / $\varepsilon$ J/ fail to trigger harmonic lowering like other non-high vowels in stressed/trigger positions (6ab) and are therefore not colour-coded like harmony triggering classes in this paper. Being unpaired for the harmony feature (i.e. since

\footnotetext{
${ }^{4}$ For etymological reasons, there is no underlying short /æ/in Old Norwegian, but short [æ] is derived from /a/ via so-called $j$-umlaut (palatalisation) and triggers harmonic lowering: e.g. /gjaf-ir/ $\rightarrow$ [gjæv-er] <giæver> 'gift'-ACC.PL.
} 
there are no*/I $v /$ ), / $\varepsilon$ J/ fail to undergo harmony in unstressed/target positions, halting non-high harmony from spreading further downstream in $(6 \mathrm{~cd}) . / \varepsilon \mathrm{J} / \mathrm{are}$ in other words phonologically inactive non-triggers but nevertheless phonologically visible blockers, neutrally blocking harmonic lowering in word-medial positions: e.g. [akker-i], not height harmonic *[akker-e]. Since / $\varepsilon$ J/ do not trigger any harmony alternation on following unstressed vowels regardless of their position, / $\varepsilon$ J/ can only ever be followed by high [i u] unstressed vowels. This form of neutral blocking is well attested in other height harmony systems; cf. e.g. Chewa (N.31; aka Chewa-Nyanja, Nyanja-Chewa, Chichewa; Downing \& Mtenje 2017), spoken in Zambia, Malawi, and Mozambique, which displays a similar form of height harmony via vowel lowering with cognate neutral blocking low vowels.

(6) Neutral blocking lax mid / $\varepsilon$ J/ vowels
a. /hell-i/ $\rightarrow$ [helll-i] <hælli> 'cave'-DAT.SG.
b. /fjôtr-i/ $\rightarrow$ [fjōtr-i] <fiotri> 'fetter'-DAT.SG.
c. /akker-i/ $\rightarrow$ [akker-i] <Akcæri> 'anchor'-ACC.SG.
d. /orrost-u/ $\rightarrow$ [orrost-u] <orrostu> 'battle'-ACc.SG.

In summary, pre-decay Old Norwegian manuscripts display a considerably complex and asymmetric vowel inventory but with fully systematic harmonising (long and short) high/mid vowels / i y u e ø o/ and two classes of neutral segments: harmonic blocking low /æ: a a:/ and neutral blocking lax mid / $\varepsilon \mathrm{J} /$. While Old Norwegian displays a rare combination of harmonic and neutral blocking vowels, its harmony patterns are internally coherent and individually well documented in other height harmony systems. For a full phonological and philological analysis of pre-decay Old Norwegian vowels and vowel harmony, see Sandstedt (2018).

\section{Visualising harmony decay in written corpora}

Using this study's grapho-phonological database, we can begin to measure and visualise harmony variation across the corpus to track the decay of the harmony patterns outlined in the preceding section. One novel way to examine harmony co-occurrence patterns in written corpora is provided by PhonMatrix visualisations, developed by Mayer, Rohrdantz, Butt, Plank \& Keim (2010) and Mayer \& Rohrdantz (2013) - accessible at http://phonmatrix.herokuapp.com/. A sample PhonMatrix visualisation of harmony co-occurrence patterns in the pre-decay manuscript (H6) is provided below in Figure 4. 


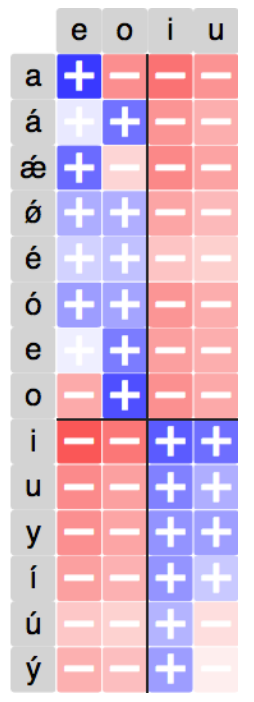

Figure 4: PhonMatrix visualisation of pre-decay Old Norwegian harmony in $\mathrm{H} 6$

The PhonMatrix method takes as an input a $V_{1}-V_{2}$ vowel matrix where each vowel pair is assigned some association measure based on their frequency of co-occurrence. Using this association measure, PhonMatrix produces coloured vowel association matrices like Figure 4 which provide an easy method for visual discovery of harmony patterns in a written corpus. In this study, I have used phi coefficient scores, a normalised measure of association based on the $\chi^{2}$ coefficient, defined as the square root of the ratio of $\chi^{2}$ to the sample size (7).

(7) $\phi=\sqrt{\frac{\chi^{2}}{n}}$

By way of a practical illustration of how this is calculated, let us assume one vowel pair: the $V_{1}$-[a] and $V_{2}$-[e] vowel matrix below in (8) with co-occurrence values $v, x, y$, and $z$ and row/column totals $a, b, c, d$. For these two vowels, the formula for the phi coefficient would be: $\phi=\frac{v \cdot z-x \cdot y}{\sqrt{a \cdot b \cdot c \cdot d}}$ This effectively measures how much more or less $V_{1}$-[a] and $V_{2}$-[e] cooccur with one another than would be expected based on their and other vowels' frequencies. 
(8) $[$ a...e] contingency table

\begin{tabular}{c|ccl} 
& {$[\mathrm{e}]$} & not-e & Total \\
\hline$[\mathrm{a}]$ & $\mathrm{v}$ & $\mathrm{x}$ & $\mathrm{a}$ \\
not-a & $\mathrm{y}$ & $\mathrm{z}$ & $\mathrm{b}$ \\
Total & $\mathrm{c}$ & $\mathrm{d}$ &
\end{tabular}

The phi coefficient ranges from -1 to 1 , where 1 represents perfect agreement, -1 perfect disagreement, and 0 indicates no relationship between the vowels. PhonMatrix then maps the phi values to a bipolar colour scale, where negative associations are red while positive associations are blue. The darkness of the colour provides a visual indicator of the strength of each $V_{1}-V_{2}$ association, with the cell receiving darker shading the farther the value is from 0 . The PhonMatrix platform currently requires each segment to be monographic (i.e. IPA representations and digraphic segments such as $a$ : or $a u$ are currently not permitted). Diphthongs are therefore not included in Figures 4/5, and long vowels are represented with acute accents ( $a=a$ : $)$. The corpus' least frequent vowels short [æ] and [ø] - occur too rarely to provide reliable results across all manuscripts and are therefore not included.

Figure 4 illustrates $V_{1}-V_{2}$ harmony associations for the pre-decay manuscript H6. This figure is based on historically harmonising contexts; that is, root-initial vowel sequences in non-compound, non-definite words with potentially lowering $\mathrm{V}_{1}$-triggers (excluding neutral, nontriggering $\mathrm{V}_{1}$-[ $\left[\begin{array}{l}\varepsilon\end{array}\right]$ ) followed by potentially harmonising $\mathrm{V}_{2}$-[i u e o] target vowels. In Figure $4, V_{1}$-triggers are listed vertically and $V_{2}$-targets listed horizontally. For clarity's sake, I have added reference lines which divide high and non-high harmony classes. As shown in Figure 4, positive and negative $V_{1}-V_{2}$ associations are very asymmetrically distributed in this manuscript: $\mathrm{V}_{2}$-[e o] vowels (the $e / o$ columns) strongly correlate with non-high vowels [a á ǽ e é ǿ o ó] while high vowels display the opposite pattern where $V_{2}$-[i u vowels (the $i / u$ columns) are positively associated with high $V_{1}$-vowels [i u y í ú ý]. Mismatched height categories are highly negatively associated (e.g. $\mathrm{V}_{1}-[-$ high $]-\mathrm{V}_{2}-[+$ high $]$ ), and this stark asymmetric pattern reveals a robust harmony system where height agreement across syllables is tightly controlled.

We can use PhonMatrix visualisations to compare the consistency of $\mathrm{V}_{1}-\mathrm{V}_{2}$ harmony associations across written corpora. Figure 5 provides a sample of six scribes, displaying three stages of harmony decay. The manuscripts in Figure 5 are ordered left to right from highest to lowest mean harmony levels, calculated by the average frequency of harmony 
in historically harmonising contexts. The transition in Figure 5 from highly asymmetric to evenly distributed vowel co-occurrence patterns illustrates the range of harmony and harmony decay in the corpus.

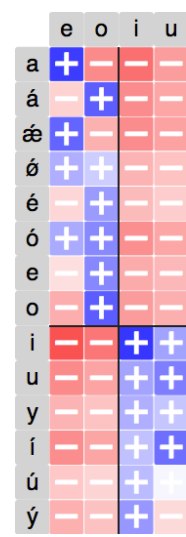

DG8

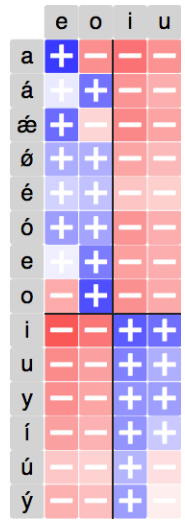

H6

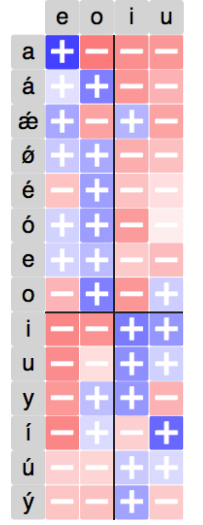

Streng_h1

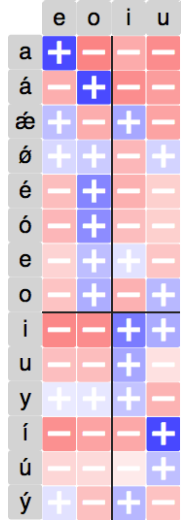

Streng_h2

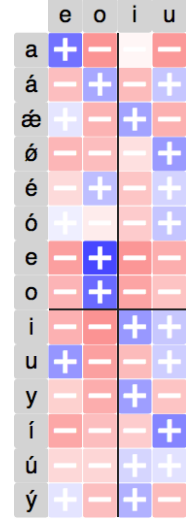

AM243

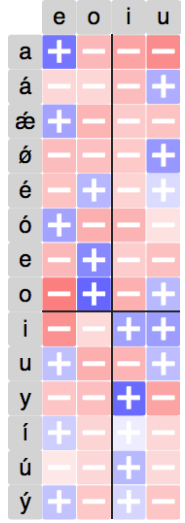

$\mathrm{H} 17$

Figure 5: Sample of PhonMatrix visualisations of Old Norwegian harmony decay

In pre-harmony decay manuscripts (DG8/H6), we observe strong asymmetric positive/negative associations between high and non-high vowels, indicating productive, robust harmony in these manuscripts. In Streng_h1, Streng_h2, and AM243, the harmony correspondences are somewhat weaker with increasing exceptions to the harmony rule: e.g. in Streng_h1 we observe positive associations between height-mismatched [ǽ...i], [о...u], [y...o], and [í...o]. From left to right in Figure 5, the asymmetric harmony pattern found in pre-decay DG8/H6 is less and less discernible across the manuscripts as the effect of harmony decay increases to completion in $\mathrm{H} 17$, which displays no recognisable relationship between $\mathrm{V}_{1}-\mathrm{V}_{2}$ height. This demonstrates the gradual decay of harmony with varying degrees of harmony variability observed in intermediary manuscripts.

Taking a broader look, Figure 6 illustrates the decay of harmony across vowel classes rather than individual vowel sequences. This figure plots mean height harmony percentages in historically harmonising $\mathrm{V}_{1}-\mathrm{V}_{2}$ sequences by $\mathrm{V}$-height class across all twelve scribes in the database. Specifically, this plot measures the frequency with which high vowels and diphthongs trigger high harmony and the extent to which tense mid and low vowels trigger non-high harmony (e.g. [liv-i] <lifi > 'live'-PRES.3.SG.SUBJ. and [gev-e] <geve> 'give'-PRES.3.SG.SUBJ., respectively); in essence, illustrating how much (0-100\%) each height class' be- 
haviour fits the pre-decay harmony generalisations outlined in section 2.2. As with the PhonMatrix visualisations above, neutral lax mid vowels are not represented in Figure 6. Moreover, because front and back vowel suffixes are lexicalised differently in the majority of intermediary and post-decay manuscripts (see section 4.3), the plot in Figure 6 only includes front vowel suffixes to avoid masking overall harmony decay trends due to asymmetric levelling of front and back vowel suffixes. Front vowel suffixes are included since their levelling patterns are more consistent across manuscripts than with back vowel suffixes, as I outline further in section 4.3. As with Figure 5, I have ordered the scribes from left to right according to descending mean harmony levels (the horizontal reference line) to illustrate the spectrum of harmony decay in the corpus. $100 \%$ harmony indicates perfect height harmony correspondence, and $50 \%$ represents no active harmony or active disharmony. No language's average harmony levels dip significantly below $50 \%$ since this would require active, iterative disharmony between syllables - i.e. something like [e...i...e...i] (cf. Harrison, Thomford \& O'Keefe 2004). This is not attested, and the medieval Norwegian corpus, which displays harmony levels from roughly $50-100 \%$, therefore represents the full spectrum of harmony to non-harmony languages.

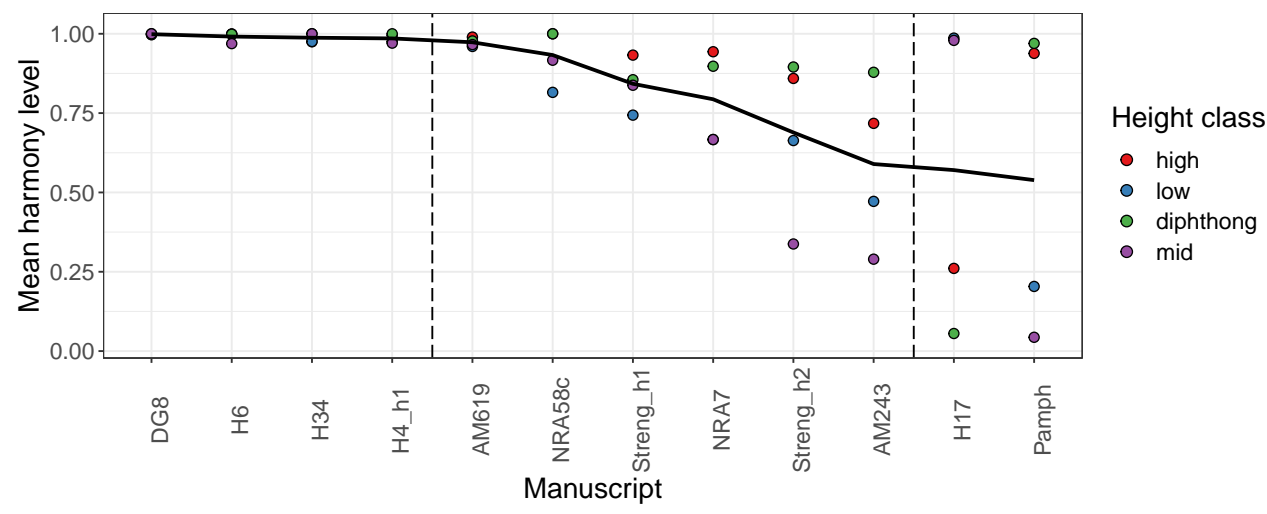

Figure 6: Mean harmony levels in historically harmonising contexts by manuscript height class in pre-decay, intermediary, and post-decay manuscripts

Figure 6 shows that lower mean vowel harmony (the horizontal reference line) is correlated with increasing dispersion in the harmony frequencies across height classes, demonstrating that harmony decay is present in the corpus. I have added vertical reference lines which group the manuscripts into pre-decay (DG8-H4_h1), intermediary (AM619- 
AM243), and post-decay stages (H17-Pamph) based on the manuscripts' relative level and variance of harmonisation as well as patterns of harmonic levelling and trisyllabic vowel reductions outlined below in sections 4.3/4.4. We go from tightly controlled, rule-governed harmony systems (high harmony and low variance), where harmony is applied essentially at ceiling (DG8-H4_h1), to fully decayed systems (low harmony and high variance) where there is no recognisable harmony distribution to speak of (H17-Pamph). The final stages of harmony decay result in levelled and non-alternating /-e -o/ or /-i, -u/ suffixes, as illustrated for H17 in (9). This is cognate to the levelled backness harmony alternations we observed in Uzbek earlier in (2). The lexicalisation of unstressed vowel height that comes with harmony decay is reflected in Figure 6 by near $0 \%$ and $100 \%$ harmonic correspondence for high (high/diphthong) vs. non-high (low/mid) vowel classes - where suffixal vowels have been levelled and are no longer alternating, resulting in stark asymmetric 'harmony' correspondence. Higher mid/low vowel harmony in Figure 6 suggests generally levelled mid vowel suffixes in H17 while higher diphthong/high vowel harmony in Pamph suggests a tendency towards levelled high vowel suffixes, but see section 4.3 for a much more detailed exploration of lexicalisation patterns in this corpus.

(9) Pre- and post-decay harmony in DG8 and H17

\begin{tabular}{|c|c|c|c|c|c|c|}
\hline $\mathrm{HIGH}$ & $\begin{array}{l}\text { hüs-i } \\
\text { skip-i }\end{array}$ & & $\begin{array}{l}\text { 'house'-DAT.SG. } \\
\text { 'ship'-DAT.SG. }\end{array}$ & $\begin{array}{l}\text { huiss-e } \\
\text { skip-e }\end{array}$ & $\begin{array}{l}{ }^{* h} \underline{u_{i} s}-\mathrm{i} \\
{ }^{*} \text { skip-i }\end{array}$ & $\begin{array}{l}\text { 'house'-DAT.SG. } \\
\text { 'ship'-DAT.SG. }\end{array}$ \\
\hline Non-/ & ljo:s-e & ${ }^{*} \operatorname{ljox} \mathrm{S}-\mathrm{i}$ & 'light'-DAT.SG. & ljoxs-e & & 'light'-DAT.SG. \\
\hline $\mathrm{HIGH}$ & segl-e & ${ }^{*}$ segl-i & 'sail'-DAT.SG. & segl-e & & 'sail'-DAT.SG. \\
\hline
\end{tabular}
(a) DG8 - [-i] / [-e]
(b) $\mathrm{H} 17-[-\mathrm{e}]$

In between pre-decay harmony and post-decay non-harmony, we observe quite a diverse range of intermediate systems. AM619 displays near-categorical harmony, but features a number of beginning signs of harmony decay, including a tendency towards levelling historically harmonising back vowel suffixes and some degree of trisyllabic vowel reductions, limiting its harmony domain (see sections 4.3/4.4). NRA58c, Streng_h1, NRA7, Streng_h2, and AM243 all display lower harmony but still relatively low variance. In particular, NRA58c and Streng_h1 appear to closely replicate pre-decay harmony - where all height classes initiate harmony at roughly equal rates - but instead of categorical harmony, the harmony rule is probabilistic, applying on average around $85-93 \%$ of 
the time in front vowel suffixes. While Streng_h2 and AM243 display less harmony and higher variance than in other intermediary and pre-decay stages, both high/non-high height classes in these manuscripts in general display greater than $50 \%$ harmony. This indicates that suffixes are still alternating, only inconsistently.

\section{The causes and pathways of harmony decay}

The foregoing section reveals a consistent and gradient transition from categorical harmony to non-harmony in the corpus. Here I explore more precisely the probable causes and ways in which harmony decay has occurred in Old Norwegian. McCollum's (2020) survey of decaying harmony languages identifies numerous potential factors resulting in changes to harmony systems. These may include external factors such as contactinduced grammatical restructuring due to the influence of divergent phonological contrasts and/or differing morphological patterns. Harmony decay may also be motivated by language-internal changes, such as the loss of harmonising morphology, changes to harmony classes via vowel mergers/splits, or the positional neutralisation of harmonising categories via vowel reductions, consonant blocking, or the development of other kinds of contextual disharmony.

The initial causation of Old Norwegian harmony decay is as of yet unclear. A wide variety of independent mechanisms are at play: levelling harmony alternations, decreasing harmony domains via trisyllabic vowel reductions, and the collapse of certain harmony/neutral blocking vowel classes via vowel mergers. It is often difficult to tease apart to what extent these individual changes motivate harmony decay or are themselves produced by it. As I have outlined in the descriptive generalisations in section 2.2, already before the onset of harmony decay Old Norwegian had multiple classes of blocking vowels that contributed to surface disharmony. Additionally, harmony was blocked by stressed syllables, was bled by other morphophonological processes such as $i$ - and $u$-umlaut, and displays complex interactions with unstressed vowel deletions (see Sandstedt 2018: $§ 5.4-5.7$ for a full exploration of Old Norwegian pre-decay harmony patterns). Altogether the surface patterns of Old Norwegian vowel harmony, though systematic, are typologically speaking very complex, and the language displays a high level of surface disharmony, featuring only between $70-75 \%$ vowel harmony in pre-decay manuscripts when not controlling for blocking or other historically disharmonic contexts. It may therefore be that Old Norwegian was, so to speak, ripe for the picking when it comes to harmony decay. In any case, 
novel independent sound changes in the language, such as the merger of harmonic and neutral blocking / e $\varepsilon$ / vowels, as well as potentially decayrelated changes such as increased harmony variability, the levelling of harmonic alternations, and unstressed vowel reductions together conspired to unravel the harmony system at different rates in different dialects over the course of the 13 th and 14 th centuries.

In his cross-linguistic survey, McCollum (2020) has identified four broad pathways by which harmony decay progresses. These include decay by 1) changing harmony classes, 2) harmony gradience and variability, 3) lexical diffusion, and 4) harmony domain reduction. Old Norwegian manuscripts display in some form each of these decay mechanisms, which I explore in detail in the following sections. Specifically, in section 4.1, I show that the degree of /e $\varepsilon$ / mergers is correlated with the decay of /e/harmony patterns across manuscripts - providing the likeliest independent motivation for harmony decay in the language. I illustrate practical examples of overall increasing harmony variability in the corpus in section 4.2 and demonstrate two important causes of decreasing harmony in the progression of harmony decay: the lexicalisation of historically harmonising morphemes in section 4.3 and the reduction of high vowels in trisyllabic forms which limits harmony domains to the initial disyllable in section 4.4. As this survey illustrates, the existing Old Norwegian digitised corpus provides a sufficient sample for tracking and visualising the causes and trajectories by which harmony gradually decayed. These findings are both supported by and contribute to the typology of harmony decay.

\subsection{Decay by mergers and changing harmony classes}

Exceptions in harmony patterns such as neutral harmony (e.g. transparency, blocking, etc.), which result in surface disharmony, are crosslinguistically strongly correlated with asymmetric inventory shape and phonological contrastivity more generally (Kiparsky \& Pajusalu 2006; Nevins 2010; Sandstedt 2018; van der Hulst 2018). It is therefore not surprising that the loss of vowel harmony is commonly associated with changes to the language's sound inventory. For example, backness harmony decay between Chaghatai and Modern Uzbek (Turkic) has been attributed to the merger of front/back /i u y u ø o/ contrasts (Harrison, Dras \& Kapicioglu 2006). Similarly, Agoi (Benue-Congo) displays tongue root harmony where the ongoing merger of ATR/RTR distinctions on high vowels /i I u v/ results in /i u/-harmony neutrality (Yul-Ifode 2003). 
Old Norwegian provides a cognate case of harmony decay involving vowel mergers. In particular, during the period of harmony decay, we observe the ongoing merger of historical tense/lax distinctions in front /e $\varepsilon$ / vowels; see Hreinn Benediktsson (1964) for an overview of this merger in Old Icelandic and Old Norwegian. The loss of this vowel contrast is predictably detrimental to Old Norwegian vowel harmony for two reasons. First, these vowels historically display differing harmony behaviours. In pre-decay manuscripts, /e/ triggers harmony while / $\varepsilon$ / does not (cf. section 2.2), and the merger of these vowel qualities results in the gradual merger of their harmony patterns, changing or collapsing these harmony classes and increasing harmony variability. Second, /e $\varepsilon$ / are among the most frequent vowels in Old Norwegian, together making up $23.21 \%$ of all vowels in root-initial syllables (cf. Figure 3c). This merger therefore results in the loss of a significant harmonic contrast in Old Norwegian and introduces a substantial amount of harmony variability, motivating harmony decay. In (10), I provide practical data which illustrate how the historical /e $\varepsilon$ / contrast is phonologically and orthographically generally maintained in DG8 but is merging in AM619. AM619 displays only the very beginnings of harmony decay, with merging ${ }^{*} e$-harmony and ${ }^{*} \varepsilon$ neutral patterns as well as some degree of harmonic levelling and limited harmony iterativity via trisyllabic vowel reductions, which I outline below in sections 4.3/4.4; otherwise AM619 displays categorical, rule-governed height harmony on par with pre-decay manuscripts (cf. Figure 6).

(10) Distinct vs. merging ${ }^{*} e /{ }^{*} \varepsilon$ vowels and vowel harmony

$$
\begin{aligned}
& \text { DG8 - non-merged /e/-<e> vs. / } / /-<æ> \\
& \text { harmonic } \quad * e \begin{array}{cc}
<\text { veg }> & \text { 'way'-ACC.M.SG. } \\
\text { <gerðe> } & \text { 'do'-PRET.3.SG. }
\end{array} \\
& \text { neutral } \quad *_{\mathcal{E}} \quad<\text { kænndi> 'know'-PRET.3.SG. } \\
& <\text { sægir> 'say'-PRES.3.sG. } \\
& \text { AM619 - merging /e } \varepsilon /-<e ~ æ>~
\end{aligned}
$$

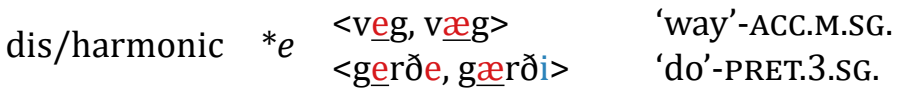

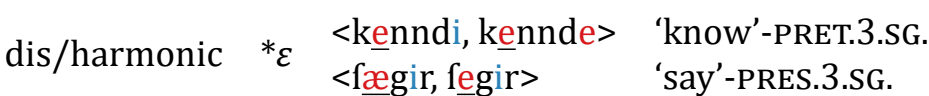

As outlined above in (10), in DG8 /e/ is fairly categorically spelled $<\mathrm{e}>$ and triggers harmonic lowering in DG8; e.g. /pess-i/ $\rightarrow$ [pess-e] $<$ pesse $>$. By contrast, $/ \varepsilon /$ is spelled $<æ>$ and does not trigger lowering:

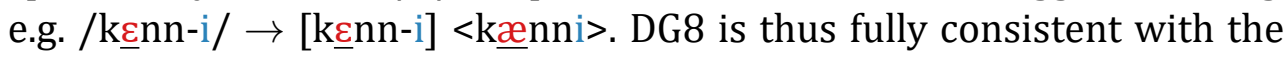


descriptive generalisations for pre-decay harmony in section 2.2. In AM619, however, we observe the ongoing merger of these vowels, both orthographically and phonologically. Historical ${ }^{*} e$ is spelled both <e> and $<æ>$ and only variably triggers harmony (e.g. historically harmonic ${ }^{*}$ ger -ðe <gerðe, gerði, gæerði>), and we observe parallel variation for ${ }^{*} \varepsilon$

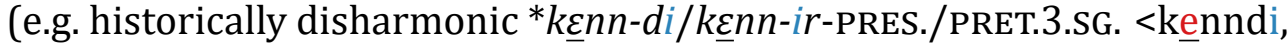
kennde, kænnir, kennir>).

It is difficult to study this merger in Old Norwegian given the limitations of Old Norwegian orthography. As outlined earlier in Table 3, most Old Norwegian scribes featured only two letters $<\mathrm{e} æ>$ for three contrasting vowel qualities [e $\varepsilon$ æ], meaning they could either a) distinguish tense $[\mathrm{e}]-<\mathrm{e}>$ vs. lax $<æ>-[\varepsilon æ]$, failing to discriminate mid [ $\varepsilon]$ and low [æ] vowel qualities, or b) they could contrast mid [e $\varepsilon]-<e>$ vs. low $<æ>-[æ]$, failing to distinguish tense [e] and lax $[\varepsilon]$ in writing. With these competing orthographic systems, $/ \varepsilon$ / is famously inconsistently represented in Old Norwegian writing already before this merger took place. Moreover, the scribes of the latter type who primarily distinguish mid $[\mathrm{e} \varepsilon]-<\mathrm{e}>\mathrm{vs}$. low <æ>-[æ] vowel qualities typically fail to display the /e $\varepsilon /$ contrast at all, even if their phonology had it. This is the case for H6, Streng_h2, and Pamph in this corpus. For such scribes, the only potential evidence of the /e $\varepsilon$ / contrast is the vowels' distinct phonological patterning with respect to height harmony. ${ }^{5}$

By focusing on manuscripts like DG8 in (10) which primarily distinguish tense $[e]-<e>$ vs. lax $[\varepsilon]-<æ>$ in writing, we can roughly measure the degree of /e $\varepsilon /$ mergers in each manuscript using the proportion of etymologically mismatched $[\mathrm{e}]-<æ>$ and $[\varepsilon]-<e>$ spellings and then compare how this relates to decaying harmony levels. Figure 8 plots the average level of harmony following /e/ in pre-decay and decaying manuscripts as well as the degree of $[e]-<e>$ vs. $[\varepsilon]-<æ>$ spelling contrasts in a number of environments which Hreinn Benediktsson (1964) has identified as potentially merging contexts. ${ }^{6}$ With the general exception of H4_h1 and NRA7, these manuscripts illustrate a fairly tight relationship

\footnotetext{
${ }^{5} \mathrm{H} 6$ is a good example of this. As demonstrated by Sandstedt (2018: 121-26), H6 displays little to no /e $\varepsilon$ / contrast in writing, but its harmony system nevertheless features clearly contrastive /e/-harmonic and / $\varepsilon$ /-neutral blocking patterns - demonstrating a phonemic contrast despite its non-contrastive orthography.

6 These are specifically:_Cr $=$ before a consonant $+r$, e.g. <bætr, gefr, mepr, tækr>; _NC $=$ before nasal + consonant, e.g. <ængi, hænndr, kuikuenndi, længst>;_r $=$ before an $r$, e.g. <ber, gera, færr, hærað>; _rC = before an $r+$ consonant, e.g. <gerðe, hværrt, klærkr, hværs $>$; and $r_{-}=$following an $r$, e.g. < reken, drepa, brænna, alldregi $>$.
} 
between decaying $\mathrm{V}_{1^{-}}$/e/ harmony patterns and the merger of /e $\varepsilon$ / vowels in writing.

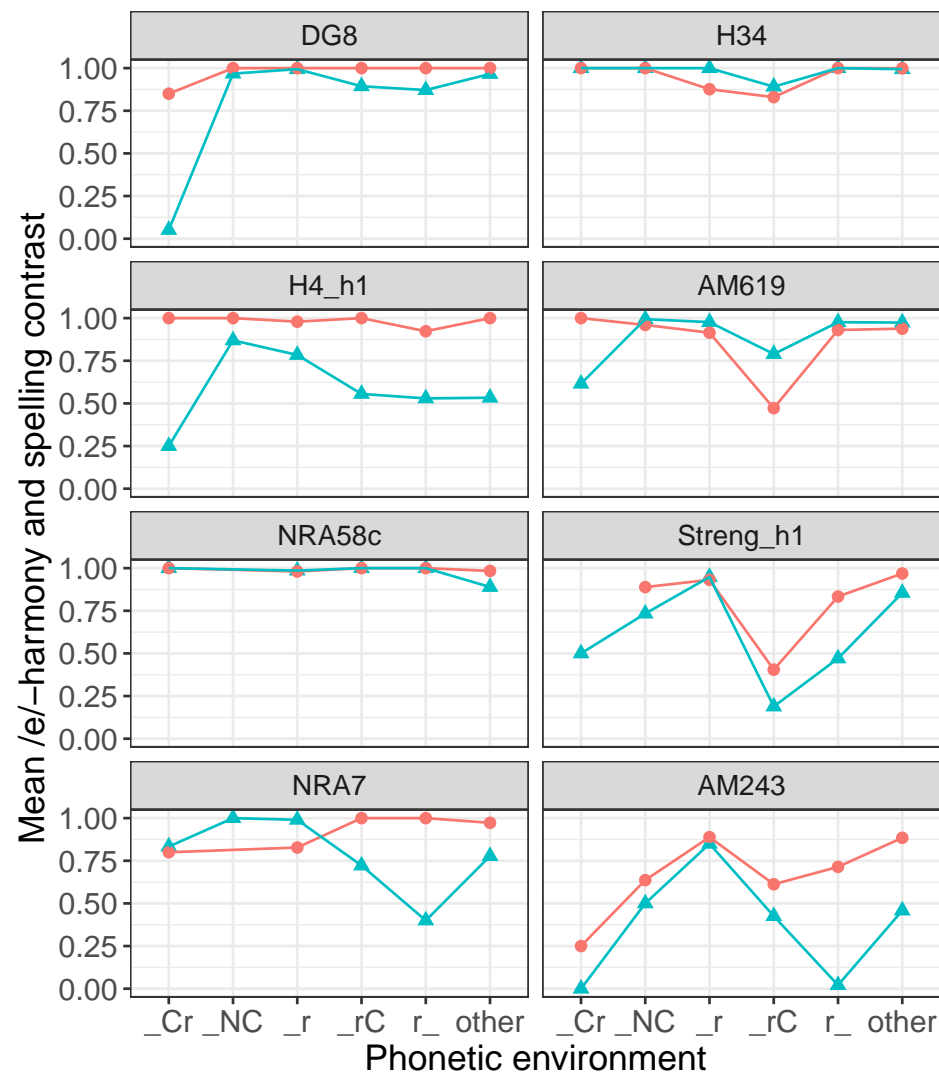

Measure

- Harmony

- Spelling contrast

Figure 8: Mean /e/-harmony and spelling contrasts by phonetic environment in /e $\varepsilon /$-contrasting manuscripts

The merger of /e $\varepsilon$ / vowels has a predictably strong effect on $V_{1}$-/e/ harmony patterns since the merger can lead to the collapse of historically distinct harmonic and neutral blocking patterns. Since the initiation of this vowel merger is presumably a sound change independent from harmony decay itself, it is likely that the loss of the /e $\varepsilon$ / contrast played an important role in motivating the loss of harmony in Old Norwegian. This hypothesis is consistent with the broader evidence. This vowel merger has occurred independently across all the Nordic languages, and its chronology aligns well with what is known of harmony decay across the Nordic dialects. However, while the /e $\varepsilon /$-merger clearly plays an important role in Old Norwegian harmony decay, it is not the only mechanism of harmony decay active in the corpus. 


\subsection{Decay by harmony variability}

As we have observed in the preceding sections, the most salient characteristic of intermediary or decaying harmony systems is harmony variability (optionality and/or gradience). Harmony is optional if a given target harmonises (completely) with some probability below 1 , and harmony is gradient if targets harmonise but only partially or incompletely. For example, Veps (Finnic) demonstrates dialectally varying degrees of frontness harmony decay, where the southern variety reportedly consistently harmonises second syllables but only optionally third-syllable vowels (Zaiceva 1981). By contrast, Kazakh and Uyghur (Turkic) have been shown to involve phonetically gradient harmony, where harmony targets display partial or incomplete assimilation, and harmony decreases monotonically the farther the target is from root-initial harmony triggers (McCollum 2019a,b). Similar to these languages, Old Norwegian harmony decay is associated with general harmony variability (see Figures 5/6). Practical examples of inconsistent harmony outcomes in the intermediary Streng_h1 manuscript are provided in (11); I give the counts of each form in the corpus in superscript.

(11) Variable harmony in decaying Streng_h1
a. [vil-di, vill-de] $<$ villdi $^{26} \sim$ villde $^{3}>$
'want'-PRET.3.SG.INDIC.
b. [hâf-ðe, haff-ði] $<$ hafðe $^{59} \sim$ hafði $^{21}>$ 'have'-PRET.3.SG.INDIC.
c. [sið-um, siðð-om] $<$ siðum $^{3} \sim$ siðom $^{2}>$ 'custom'-DAT.PL.
d. [go:ð-om, go:ð-um] $<$ goðom $^{12} \sim$ goðum $^{3}>$ 'good'-DAT.PL.

Streng_h1 displays variable harmonisation, but because of the philological nature of the data it is uncertain whether these data reflect optional categorical harmony like Southern Veps or incomplete subphonemic assimilation like Kazakh or Uyghur. Irrespective of potentially gradient harmony variation, Old Norwegian scribes were forced to represent harmony in writing in categorical terms using discrete high and mid $<i \mathrm{u}>$ and $<e$ o $>$ vowel letters. We can thus observe inconsistent harmony, but distinguishing gradient vs. optional harmony variation is obviously much more challenging in historical records. In any case, it stands to reason that increasing harmony variability, either categorically or gradiently, across vowel categories reduces the accuracy of phonological harmony generalisations and decreases the overall rate of harmony, making the survival of a harmony system less likely. 


\subsection{Decay by lexical changes}

Harmony variability like that observed in Old Norwegian is commonly accompanied by lexical changes, such as levelling harmony alternations on specific affixes, resulting in fewer harmonising morphemes. For example, Chaghatai displays harmony with significant lexical restrictions, where reportedly around half of high suffixes are subject to labial harmony (Eckmann 1966: 33-36; Bodrogligeti 2002: 14-16). Similarly, pre-decay Old Norwegian displays a wide variety of affixes (descended from compounds and enclitics) which fail to harmonise, such as stressed derivational suffixes and definite suffixes (see Sandstedt 2018: §5.5-5.7). As harmony decay progresses, we observe increasing levelling of harmony alternations in harmonising morphemes with particular asymmetries in the treatment of front and back vowel suffixes.

In Figures 9-11 below, I plot the degree of harmony on front and back vowel suffixes following high and non-high vowel harmony triggers in pre-decay, intermediary, and post-decay manuscripts. For ease of interpretation, I represent high and non-high vowel harmony triggers in these graphs by the verbal stems /skyl-, mæ:l-/ 'should, speak'. Front and back vowel harmony targets are represented by the 3rd person singular/plural preterite suffixes /-ði -ðu/, but note that the patterns of lexicalisation in this corpus do not appear to depend on part of speech. The data below represent all inflectional suffixes across all word classes.

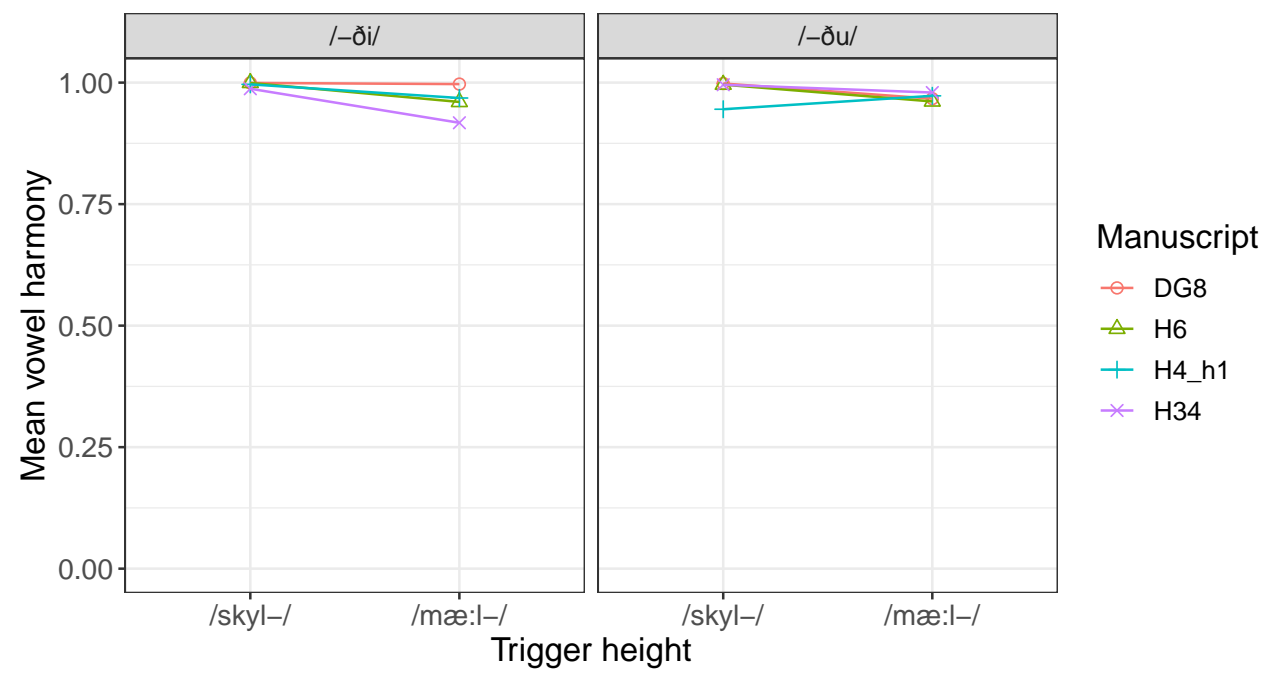

Figure 9: Categorical harmony in non-levelling, pre-decay manuscripts 
In Figures 9-11, any asymmetry or positive/negative slope in the level of harmony between high and non-high /skyl-, mæ:l-/ harmony triggers indicates some lexicalisation of inflectional suffixes towards either fixed high /-ði, -ðu/ or non-high /-ðе, -ðо/. The direction of the asymmetry points to the direction of levelling. If harmony levels are higher on the left over [+high] /skyl-/ - as they are for nearly every intermediary manuscript below in Figure 10 on front vowel suffixes like /-ði/ - then this is evidence of levelling towards non-alternating high vowel suffixes: e.g. [skyl-di] and [mæ:l-ti] instead of height harmonic ${ }^{*}\left[\right.$ mæ:l-to] $^{7}{ }^{7}$ If harmony levels are higher on the right above [-high] /mæ:l-/ - as is the case for back harmony targets like /-ðu/ in Streng_h1 in Figure 10 - then this is evidence of levelling towards non-alternating mid vowel suffixes: e.g. [mæ:lo-to] and [skyl-do] instead of height harmonic * [skyl-du].

In pre-decay manuscripts above in Figure 9, we predictably observe little evidence of harmonic levelling. Both front and back inflectional suffixes harmonise fairly categorically to both high and non-high harmony triggers in each manuscript. By contrast, among intermediary stages of Old Norwegian vowel harmony decay in Figure 10, we observe varying degrees of harmonic levelling in all manuscripts. Specifically, there is consistently more harmony in the left graph in Figure 10 in all intermediary manuscripts on front vowel suffixes like /-ði/ following high $\mathrm{V}_{1}$-harmony triggers. Put simply, there is much more [-i] than [-e] in the corpus than would be expected based on historical harmony generalisations - indicating significant levelling towards high front vowel suffixes: e.g. [skyl-di] and [mæ:l-ti], instead of *[mæ:l-te]. The exception is AM619, which shows only the very beginning signs of harmony decay and still displays near categorical height harmony on front vowel suffixes, with equal rates of harmonisation following high and non-high harmony triggers.

Though each of the other intermediary manuscripts displays trends towards levelling front vowel suffixes as high /-ði/, the degree of overall harmony varies considerably, matching the overall level of harmony decay observed earlier in Figure 6. For instance, NRA58c which is in the early stages of harmony decay (cf. Figure 6) still displays over $80 \%$ harmonic lowering in /mæ:l-ði/-type cases. By contrast, less than half of /mæ:l-ði/-type forms are harmonic in AM243 which represents a late stage of harmony decay. Back vowel targets (the right-hand plot) display

\footnotetext{
${ }^{7}$ Note that the dental consonant of these suffixes generally occludes and assimilates to preceding consonants for voicing; e.g. [spur-ði, rud-di gæ:t-ti] 'ask, clear, watch over'PRET.3.SG.
} 


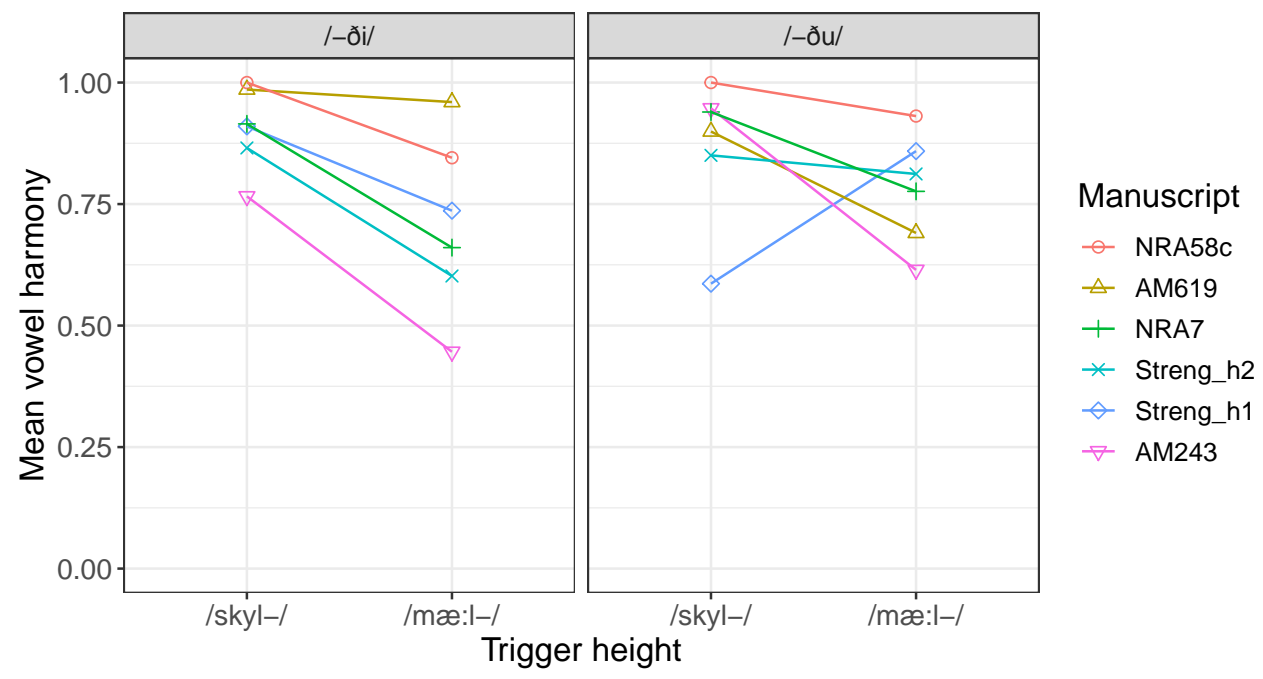

Figure 10: Varying harmony levels on front/back harmony targets following non-/high harmony triggers in intermediary decaying manuscripts

much more variation across the manuscripts, with 1) fairly even levels of harmonisation in NRA58c and Streng_h2; 2) levelling towards /-ðu/ in AM619, NRA7, and AM243; and 3) levelling towards /-ðо/ in Streng_h1.

Though AM619 displays nearly categorical harmonisation in all other contexts, it features significantly less harmonic lowering on back vowel targets in the right graph in Figure 10. This represents a trend towards levelling back vowel suffixes as high /-u/ - especially before a following $/ \mathrm{m} /$, as in the dative plural suffix in nouns/adjectives or the 1 st person plural /-um/ suffix in verbs. This leaves around 30\% disharmonic back vowel inflectional suffixes in AM619 following lowering triggers like /mæ:l-/. This levelling shows no clear morphological conditioning and is displayed in all word types: e.g. [go:ð-um] <goðum> 'good'DAT.PL.; [ger-ðu] <gerðu> 'do'-PRET.3.PL.INDIC.; [hert-um] <hetum> 'call'PRET.1.PL.INDIC.; and [klæ:ð-um] <clæðum> 'clothes'-DAT.PL.; instead of height-harmonic * [go:ð-om, ger-ðo, hert-om, klæ:ð-om].

As mentioned above, the observed height and backness asymmetries among intermediary manuscripts in Figure 10 reflect different directions of ongoing levelling of front and back vowel suffixes. Below in (12), I provide practical summaries of each manuscripts' lexicalisation patterns using preterite verbal inflections. In summary, though these intermediary manuscripts of course display variable harmony (cf. section 4.2), we see in general tendencies towards the levelling of all suffixes as high /-i, -u/ in AM243 and NRA7: e.g. [gæ:t-ti, gæ:t-tu], not * [gæ:t-te, gæ:t-to] 
(12ab). Streng_h1 displays a tendency towards mixed, non-alternating /-i, -o/: e.g. primarily [mæ:loti, skyl-do], not *[mæ:l-te, skyl-du] (12gh). Streng_h2 and NRA58c illustrate mixed cases with front vowel suffixes levelling towards non-alternating /-i/ as in the other manuscripts, but where back vowel suffixes still undergo harmony, showing roughly equal rates of harmonisation: e.g. harmonic [vil-du, mæ:lo-to], but disharmonic [mæ:loti], not *[mæ:l-te] (12cd). Finally, AM619 displays the alternative pattern with back vowel suffixes levelling towards non-alternating /-u/ as in AM243/NRA7, but where front vowel suffixes still undergo harmony: e.g. harmonic [vil-di, mast-te], but disharmonic [ma:t-tu], not *[ma:t-to] (12ef).

(12) Different trajectories of harmonic levelling in intermediary harmony manuscripts
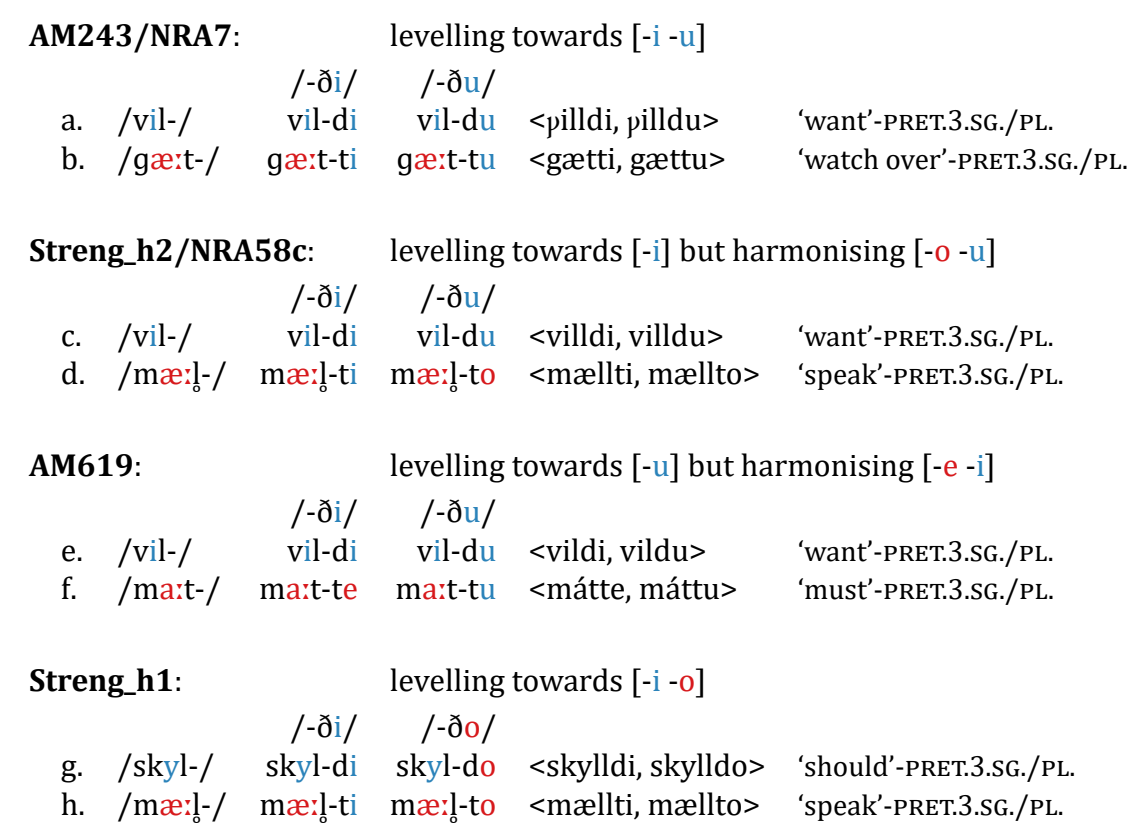

As harmony decay progresses, the final result is fully levelled harmony alternations, as illustrated by post-decay languages where historically alternating suffixes are levelled to one or the other harmony class. For example, as shown earlier in (2), the historically alternating front/back plural suffixes [-lar] / [-ler] still found in modern Turkish have been lexicalised as non-alternating, back [-lar] in Uzbek (2b): e.g. [do'st-lar] and [et-lar], not harmonic *[et-ler] (Csató \& Johanson 1998; Sjoberg 1963). Old Norwegian dialects display a number of alternative outcomes of harmony decay; the two post-decay manuscripts in the current corpus 
illustrate two of these. As shown below in Figure 11, the two manuscripts Pamph and H17 display opposite patterns with respect to front vowel suffixes like /-ði/, being lexicalised as high /-ði/ in Pamph but as nonhigh /-ðe/ in H17. In contrast, back vowel suffixes such as /-ðu/ in the right graph of Figure 11 display very similar levelling in both manuscripts towards high vowels: e.g. [skyl-du] and [mæ:l-tu] instead of *[mæ:l-to]. However, note that the distribution between high and non-high back suffixes is less polarised than for front vowel suffixes in both manuscripts, each displaying at least $30 \%$ mid vowel back suffixes.

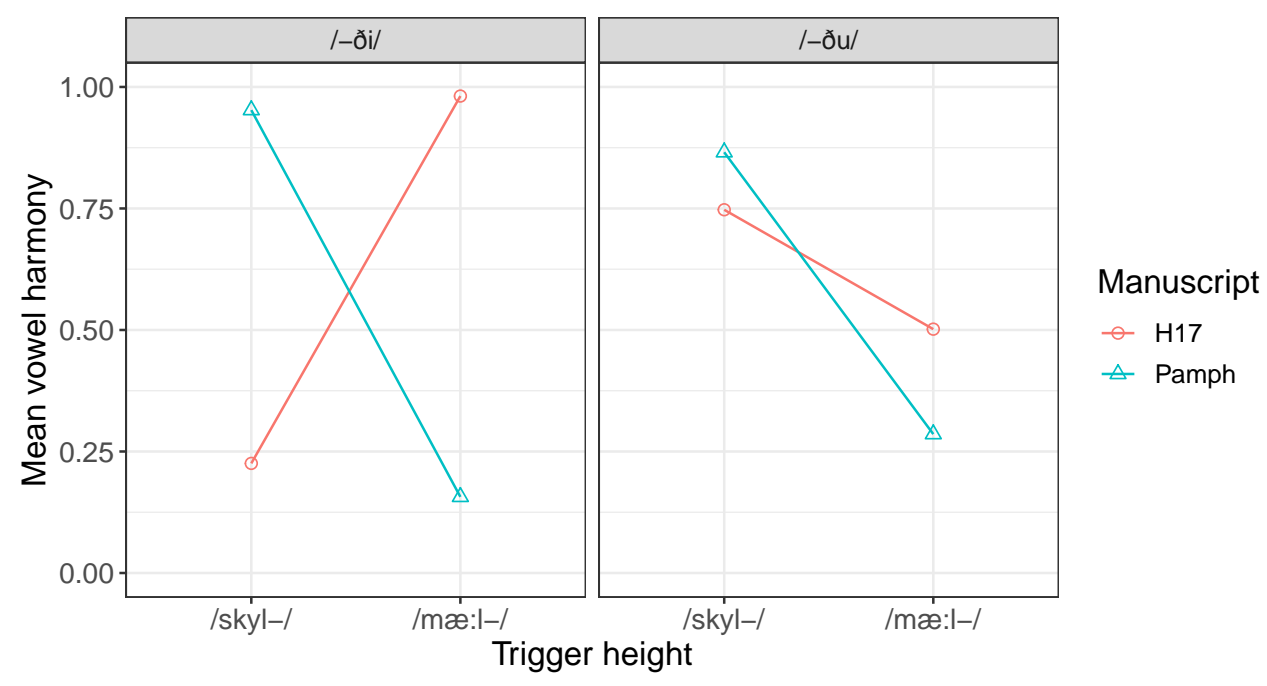

Figure 11: Highly asymmetric harmony levels following non-/high harmony triggers as a result of lexicalisation in post-decay manuscripts

In summary, Old Norwegian vowel harmony decay is characterised by a wide variety of lexicalising patterns. The current corpus illustrates that levelling historically harmonising suffixes sets in early in harmony decay, attested to some degree in all pre-, intermediary, and post-decay stages of this sound change. The progressive diffusion of suffixes to nonalternating classes leaves progressively fewer morphemes subject to harmony. This reduces the overall rate of harmonisation and increases the dispersion between vowel classes' height correspondence, which is visualised very clearly by the kind of trumpet shape of dispersing harmony patterns in Figure 6. These effects of decreasing harmony frequency and increasing variance in vowels' harmony behaviours motivate further harmony decay. 


\subsection{Decay by reducing harmony domains and vowel reductions}

A fourth common pathway of harmony decay is the reduction in harmony domains. For example, as mentioned earlier, vowel harmony in Southern Veps is largely limited to the initial disyllable (Zaiceva 1981). Like Veps, Crimean Tatar dialects also display variation in harmony domains (Kavitskaya 2013; McCollum \& Kavitskaya 2018). Southern Crimean Tatar has robust, pre-decay labial harmony on all non-initial high vowels: e.g. [tuz-luy-u] 'salt'-NMZR-POSS.3.sG. In the central dialect, by contrast, the harmony domain is limited only to the initial disyllable, failing to apply to third-syllable vowels: e.g. [tuz-luy-u]. Finally, Northern Crimean Tatar has lost labial harmony altogether, and initial syllables are optionally unrounded: e.g. [tuz-luy-u] or [tuz-luy-u]. In addition to restrictions on the harmony domain itself, harmony iterativity may also be limited via vowel reductions in unstressed positions. For instance, Mongolian languages such as Khalkha or Kalmyk Oirat have root-initial stress similar to Old Norwegian and display reduction of short unstressed vowels which increases the further the unstressed vowel is removed from the stressed syllable. Binnick (1991: §3.4) posits that such reduced vowels are neutral to vowel harmony, masking harmony effects - therewith contributing to harmony decay.

Non-iterative harmony has been recorded for certain Old Norwegian material; for example, Hagland (1978: 144) reports that 14th-century Trøndelag charters in general fail to harmonise third-syllable vowels: e.g. [stu:k-u-n-ne], not *[stu:k-u-n-ni] 'chapel'-DAT.SG.-DEF.-DAT.F.SG, and we commonly observe similar partially harmonic forms in the current corpus' decaying harmony manuscripts, such as Streng_h2 [lirtil-le] <litille> 'little'-DAT.F.SG. or [nokkur-o] <nockuro> 'some'-DAT.N.SG. Rather than reductions on the harmony domain like Crimean Tatar or Veps where thirdsyllable vowels surface unchanged, Hagland (1978) posits that these data reflect vowel reductions, similar to Mongolian. In other words, Old Norwegian underlying high vowels /i u/ are lowered or centralised to [e o] in trisyllabic positions. This is confirmed by the current corpus, where decaying or decayed harmony manuscripts display significantly more $\mathrm{V}_{3}$ [e o] than $\mathrm{V}_{3}$-[i u], which contributes to decreased harmony in high vowel contexts - e.g. [lixtil-le] rather than pre-decay [lirtil-li] - and increased height correspondence in non-initial, non-high vowel sequences where harmony historically has failed to apply. For example, in pre-decay manuscripts, /J/ neutrally blocks harmonic lowering and can only be followed by high [i u] vowels - e.g. H6 [kastəðu] <kastaðu> - but as vowels are increasingly reduced in trisyllabic positions, we observe an increase 
in non-blocked forms, such as Streng_h1/Streng_h2 [kastıðo] <kastaðo, kastoðo>; cf. pre-decay harmony and neutral harmony generalisations in section 2.2.

To tease apart the relationship between sequence position and potential vowel reductions on harmony patterns, I conducted a generalised linear regression analysis with a three-way interaction between sequence number, trigger V-height, and harmony type. Harmony type in this model distinguishes the three stages of harmony decay previously outlined in section 3: i.e. pre-decay harmony in DG8, H6, H34, H4_h1; intermediary decaying harmony in AM619, NRA58c, Streng_h1, NRA7, Streng_h2, and AM243; and post-decay non-harmony in H17 and Pamph (cf. Figure 6). Both sequence number and trigger V-height predictor variables are categorical with two levels. V-height distinguishes sequence initial high/non-high vowels (e.g. /lif-/ vs. /gef-/), and sequence number $1 / 2$ represents root-initial and non-initial vowel sequences (e.g. $V_{1}-V_{2}$ vs. $V_{2}-$ $\mathrm{V}_{3}$ ), such as $\{\text { listil }\}_{1}$-li and liz\{til-li $\}_{2}$. The model summary is provided in Table 4 with examples illustrating the four harmony contexts indicated by each term. Corresponding visualisations are given in Figure 12.

The intercept in Table 4 estimates the log odds of harmony in predecay manuscripts in root-initial vowel sequences $\left(V_{1}-V_{2}\right)$ where the $V_{1}$ is non-high: e.g. in words such as [gev-e] <geve> 'give'-PRES.3.SG.SUBJ. or $[\text { \{morgon }\}_{1}$-en-n] <morgonenn> 'morning'-ACC.-DEF.-ACC.M.SG. The other terms in Table 4 compare how much more or less likely harmony is when compared to the intercept. For instance, Table $4 \mathrm{~b}$ compares how much more or less likely harmony is in lif-V-type words than in gef-V-type words at each stage of harmony decay. Positive estimates indicate harmony is more likely in the relevant context while negative estimates represent less probable harmony. For instance, in Table $4 \mathrm{a}$, we predictably observe a significant negative effect of harmony type in gef-V-type $\mathrm{V}_{1}$-[-high] contexts for intermediary $(E=$ $-0.242, z(45334)=-50.90, p<0.001)$ and post-decay manuscripts $(E=-0.177, z(45334)=-27.60, p<0.001)$. This illustrates that decaying and post-decay systems have significantly less harmonic lowering in words such as /gef-i/ $\rightarrow$ [gev-e] than in pre-decay stages. Moreover, the model picks up on more specific pathways of harmony decay in the corpus. For example, the overall tendency towards levelling suffixes as high /-i, -u/ vowels in decaying systems explored in section 4.3 is reflected via a positive effect of $\mathrm{V}_{1}-[+$ high] in intermediary manuscripts in Table $4 \mathrm{~b}(E=0.135, z(45334)=19.83, p<0.001)$. In other words, because suffixes are being lexicalised as high [-i, -u] in many decaying manuscripts, non-initial $\left(\mathrm{V}_{2}\right)$ vowels are significantly more likely to har- 


\begin{tabular}{|c|c|c|c|c|c|}
\hline & Term / Harmony Context & Estimate & SE & z-value & $p$ \\
\hline \multirow[t]{2}{*}{ a. } & $V_{1}-[-$ high $]=g \underline{e f}-\mathrm{V}$ & & & & \\
\hline & $\begin{array}{l}\text { pre-decay (intercept) } \\
\text { intermediary } \\
\text { post-decay }\end{array}$ & $\begin{array}{r}0.961476 \\
-0.241780 \\
-0.177115\end{array}$ & $\begin{array}{l}0.003228 \\
0.004750 \\
0.006417\end{array}$ & $\begin{array}{r}297.815 \\
-50.899 \\
-27.600\end{array}$ & $\begin{array}{l}<0.001 \\
<0.001 \\
<0.001\end{array}$ \\
\hline \multirow[t]{2}{*}{ b. } & $\mathrm{V}_{1}-[+$ high $]=$ liff-V & & & & \\
\hline & $\begin{array}{l}\text { pre-decay } \\
\text { intermediary } \\
\text { post-decay }\end{array}$ & $\begin{array}{r}0.026203 \\
0.134530 \\
-0.369407\end{array}$ & $\begin{array}{l}0.004614 \\
0.006786 \\
0.009255\end{array}$ & $\begin{array}{r}5.680 \\
19.825 \\
-39.913\end{array}$ & $\begin{array}{l}<0.001 \\
<0.001 \\
<0.001\end{array}$ \\
\hline \multirow[t]{2}{*}{ c. } & $\mathrm{V}_{2}$-[-high $]=$ lok-en-nV & & & & \\
\hline & $\begin{array}{l}\text { pre-decay } \\
\text { intermediary } \\
\text { post-decay }\end{array}$ & $\begin{array}{l}0.031159 \\
0.063304 \\
0.018075\end{array}$ & $\begin{array}{l}0.009701 \\
0.014812 \\
0.016894\end{array}$ & $\begin{array}{l}3.212 \\
4.274 \\
1.070\end{array}$ & $\begin{array}{l}<0.001 \\
<0.001 \\
=0.285\end{array}$ \\
\hline \multirow[t]{2}{*}{ d. } & $\mathrm{V}_{2}-[+$ high $]=$ lið-inn-nV & & & & \\
\hline & $\begin{array}{l}\text { pre-decay } \\
\text { intermediary } \\
\text { post-decay }\end{array}$ & $\begin{array}{l}-0.029649 \\
-0.251813 \\
-0.156054\end{array}$ & $\begin{array}{l}0.025647 \\
0.039270 \\
0.041008\end{array}$ & $\begin{array}{l}-1.156 \\
-6.412 \\
-3.805\end{array}$ & $\begin{array}{l}=0.248 \\
<0.001 \\
<0.001\end{array}$ \\
\hline
\end{tabular}

Table 4: Result summary: coefficient estimates, standard errors, $z$-scores, and significance level $p$ for all predictors in the analysis

monise in /lif-i/ 'live'-PRES.3.SG.SUBJ. than in /gef-i/-type contexts. While levelling suffixes as high $[-\mathrm{i},-\mathrm{u}]$ generally boosts harmony levels in high vowel contexts like lif-V, harmony is actually significantly less likely in trisyllabic positions following non-initial $\mathrm{V}_{2}$-[+high] vowels in both intermediary $(E=-0.252, z(45334)=-6.41, p<0.001)$ and post-decay manuscripts $(E=-0.156, z(45334)=-3.81, p<0.001)$. That is, the partially harmonic form [liðin-ne] is in general more likely than the fully harmonic [liðin-ni] 'shut'-PRET.PART.-DAT.F.SG. in decaying and postdecay manuscripts. By contrast, harmony is boosted in trisyllabic positions in [-high] lok-en-nV-type contexts for intermediary manuscripts $(E=0.063, z(45334)=4.27, p<0.001)$. This demonstrates clear evidence of reducing /i u/ $\rightarrow$ [e o] in trisyllabic positions.

These effects are visualised in Figure 12, which plots the mean level of harmony across each harmony type in the four relevant contexts: 1 ) following non-high $\mathrm{V}_{1}$-vowels, e.g. [gev-e] <geve> 'give'-PRES.3.SG.SUBJ. or [\{loken $\}_{1}$-ne] <lokenne> 'shut'-PRET.PART.-DAT.F.SG.; 2) following $\mathrm{V}_{2}$ [-high] vowels, e.g. [lo $\left.\left.\{\text { ken-ne }\}_{2}\right] ; 3\right)$ following $\mathrm{V}_{1}-[+$ high $]$ vowels, 
e.g. [liv-i] <lifi> 'live'-PRES.3.SG.SUBJ. or [\{liððin $\}_{1}$-ni] 'pass'-PRET.PART.DAT.F.SG.; and 4) in non-root-initial vowel sequences following $V_{2}$-high vowels, e.g. [li $\left.\{\text { ðin-ni }\}_{2}\right]$. In these plots, a negative slope between $V_{1}$ [+high] and $\mathrm{V}_{2}$-[+high] contexts evidences reductions of /i u/ $\rightarrow$ [e o] in trisyllabic positions. This is demonstrated already in the otherwise non-decaying manuscript fragment H4_h1, which shows decreased harmony rates in non-root-initial $\mathrm{V}_{2}-[+$ high $]$ environments compared to root-initial $\mathrm{V}_{1}$-[+high] harmony contexts.

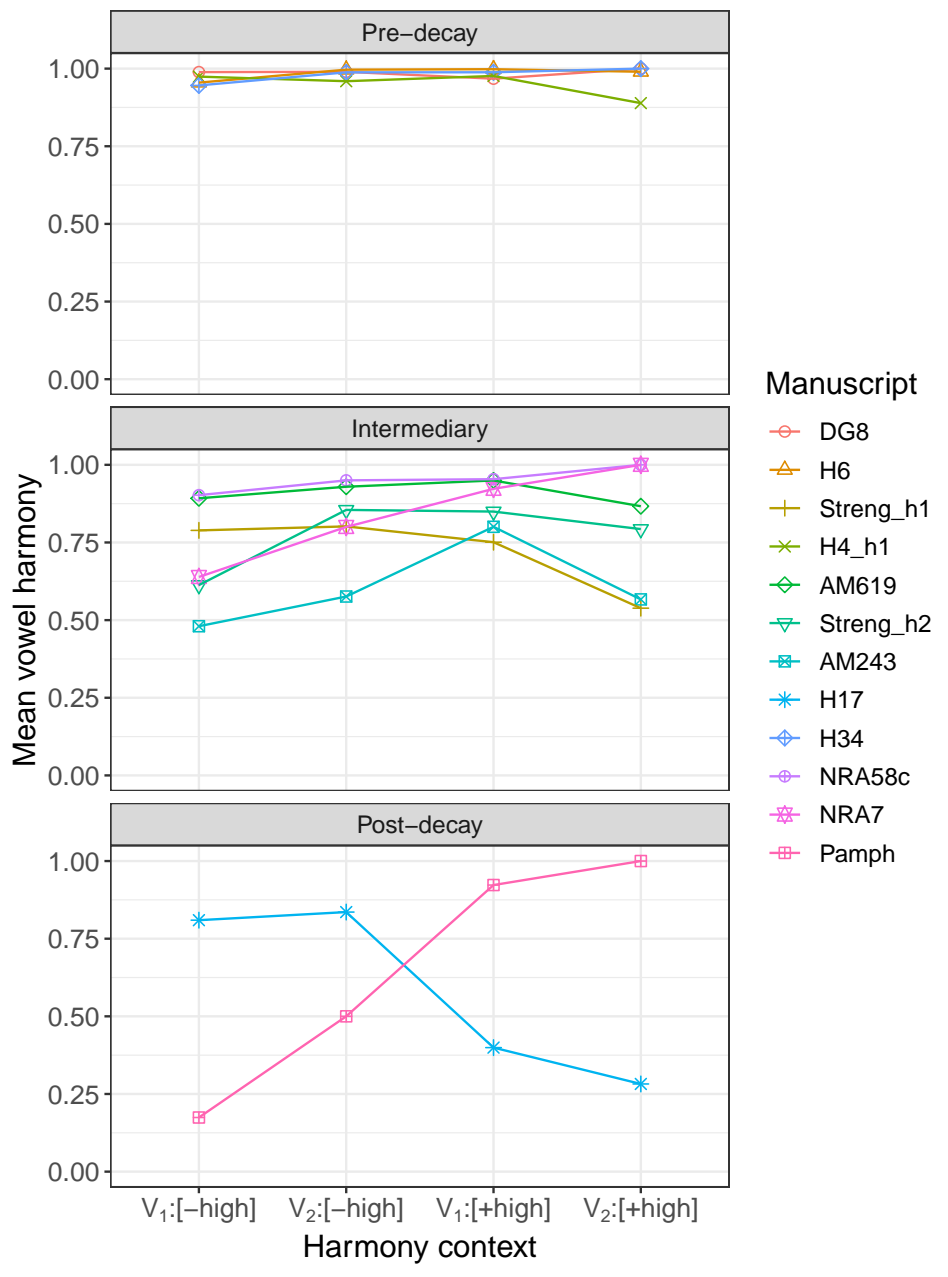

Figure 12: Contribution of sequence number and trigger vowel height to harmonic correspondence in pre-decay, intermediary, and post-decay manuscripts

The intermediary manuscripts in Figure 12 display strong effects of vowel harmony decay, with generally considerably reduced harmony 
rates in all harmony contexts compared to pre-decay manuscripts. However, note that all high and non-high harmony environments in these manuscripts display harmony at or above $50 \%$, indicating that unstressed vowels still undergo height harmony alternations, only inconsistently. Streng_h1 and AM243 show significant signs of $\mathrm{V}_{3}$-reductions, with substantially lower harmony following $\mathrm{V}_{2}-[+$ high $]$ vowels when compared to $V_{1}$-[+high] vowel contexts: i.e.. [li $\left.\{\text { ðin-ne }\}_{2}\right]$ compared to [\{liððin $\}_{1}$-ne]. Streng_h2 and AM619 additionally show significant, albeit weak, signs of $\mathrm{V}_{3}$-reductions whereas NRA7 and NRA58c display either roughly equal or increased harmony rates in $\mathrm{V}_{3}$-positions as a result of levelling inflectional suffixes as high /-i, -u/ (cf. section 4.3). Finally, H17 and Pamph on the right in Figure 12 illustrate two opposing post-decay systems where the majority of suffixes are either levelled high /i u/ as in Pamph or nonhigh /e o/ as in H17, resulting in significantly asymmetric non-/high harmony levels where either high or non-high categories display significantly lower than 50\% harmonic correspondence; see section 4.3 for a more detailed exploration of these levelling patterns. H17 shows levelled, non-alternating front /-e/, and to a lesser extent back /-o/, vowels. This is reflected in Figure 12 by high harmony levels following [-high] vowels and very low harmony elsewhere. Pamph shows the opposite pattern, with levelled /i u/ vowels, as evidenced by low harmony levels following [-high] and higher harmony elsewhere. Decreased harmony levels following $\mathrm{V}_{2}-[+$ high $]$ vowels in $\mathrm{H} 17$ shows that this scribe additionally features considerable trisyllabic vowel reductions. While it is clear that Pamph displays lexicalised high vowel suffixes with markedly greater harmony levels in high-vowel contexts, we cannot effectively evaluate whether Pamph display trisyllabic vowel reductions. At only 4,470 words, Pamph is the smallest manuscript fragment in this study's corpus, and trisyllabic and longer words combined make up only $3.7 \%$ of the corpus (cf. Figure 3b). Further dividing these non-initial vowel sequences by trigger V-height in strictly harmonising contexts leaves too small a sample to say anything concrete about word-initial vs. non-initial harmony frequencies in this manuscript fragment.

In summary, much of the Old Norwegian corpus displays evidence of harmony decay via $\mathrm{V}_{3}$-vowel reductions. This results in decreased harmony iterativity in high vowel contexts outside the initial disyllable: e.g. [lixtil-le] rather than pre-decay [lixtil-li]. Such reductions have been found to set in early in Old Norwegian harmony decay - evidenced in the otherwise non-decaying H4_h1 manuscript fragment - and may persist after harmony has been lost, as shown by post-decay H17. 


\section{Conclusions}

Vowel harmony is considered to be one of the most natural, easily acquired, and historically stable processes that occur in phonology. Although harmony processes are typologically very common, much remains unclear regarding how harmony systems emerge and decay over time. In particular, the factors which motivate the loss of vowel harmony and the pathways by which this rare sound change occurs are poorly understood since no consistent historical record has yet been analysed which displays the full progression of harmony decay (McCollum 2015, 2020; Kavitskaya 2013, Bobaljik 2018).

In this paper, I have presented a detailed corpus study of vowel harmony decay as preserved in recently digitised 13th- and 14th-century Old Norwegian manuscripts. This is the first corpus which illustrates a detailed and coherent transition from fully harmonic to non-harmonic stages, distinguishing 1) robust, productive harmony, 2) intermediary, decaying systems, and 3) fully decayed, non-harmony. Though the decay of Old Norwegian vowel harmony has long been recognised in Norse philological circles (Flom 1934b, Seip 1955, Hødnebø 1977, Hagland 1978), it has yet to receive any detailed linguistic study. The philological nature of Old Norwegian texts introduces unique problems in securing reliable phonological data. To control for potential noise in the data common in medieval orthography, I have annotated the data with etymological and other grapho-phonological cross-references. This approach accounts for spelling variation, both which is linguistically motivated (e.g. ongoing sound mergers, variable sound processes, etc.) as well as purely orthographically motivated variation (e.g. many-to-one soundto-letter correspondences, vocalic consonantal spellings, etc.). Using a sample of twelve recently digitised 13th- and 14th-century manuscripts and manuscript fragments, I have provided a vowel harmony database of 275,554 words with 289,070 individual etymologically and linguistically annotated pairwise vowel sequences.

In addition to providing novel methods for tracking and visualising phonological change in progress in written corpora, this paper has explored the factors motivating harmony decay in Old Norwegian and the pathways this sound change has taken, as evidenced by intermediary and post-decay manuscripts. In particular, the merger of historically harmonic /e/ and neutral blocking / $\varepsilon$ / vowels motivates the collapse of historically distinct harmony patterns and likely provided the initial motivation for general harmony decay in Old Norwegian. Over the course of harmony decay, the corpus displays additionally a) increasing harmony 
variability across all vowel categories, b) the lexicalisation of historically harmonising morphemes, and c) trisyllabic vowel reductions. Each of these decay mechanisms contributes to decreasing harmony rates, limiting harmony iterativity, and increasing the dispersion between different height classes' harmony behaviours to the point of completed harmony decay. The composite result of these individual sound changes is a remarkably gradient transition from pre-decay to post-decay stages of the language. Following McCollum's (2020) recent survey of decaying harmony systems, I have shown that the individual mechanisms of Old Norwegian harmony decay are all typologically consistent with other decaying or decayed harmony languages. This study of Old Norwegian harmony decay in progress provides therewith good empirical confirmation of suspected causes and pathways of harmony decay as well as valuable diagnostics for identifying and analysing harmony change in other languages.

\section{Comments invited}

PiHPh relies on post-publication review of the papers that it publishes. If you have any comments on this piece, please add them to its comments site. You are encouraged to consult this site after reading the paper, as there may be comments from other readers there, and replies from the author. This paper's site is here:

https://doi.org/10.2218/pihph.5.2020.4417

\section{Acknowledgements}

Parts of this research were presented at the Fourth Edinburgh Symposium on Historical Phonology (December 9-10 2019), and I am very grateful to the hosts and audiences on this occasion. I would like to thank particularly Pavel Iosad, Patrick Honeybone, and Adam McCollum for valuable comments and suggestions on previous drafts of this paper. Any remaining faults are mine alone.

\section{Author's contact details}

Jade J. Sandstedt

UiT The Arctic University of Norway 
Department of Language and Culture

Tromsø, Norway

jade.j.sandstedt@uit.no

\section{References}

Altan, Asli. 2007. The acquisition of vowel harmony in Turkish. Paper presented at the 4th Old World Conference in Phonology, University of the Aegean, 18-21 January.

Anderson, Gregory. 1998. Historical aspects of Yakut (Saxa) phonology. Turkic languages 2(2). 1-32.

Barnes, Michael P. 1994. The runic inscriptions of Maeshowe, Orkney. Uppsala: Institutionen för nordiska språk, Uppsala Universitet.

Binnick, Robert I. 1991. Vowel harmony loss in Uralic and Altaic. In William G. Boltz \& Michael C. Shapiro (eds.), Studies in the historical phonology of Asian languages (Current issues in linguistic theory 77), 35-52. Amsterdam: John Benjamins.

Bobaljik, Jonathan David. 2018. Disharmony and decay: Itelmen vowel harmony in the 20th century. In Roberto Petrosino, Pietro Cerrone \& Harry van der Hulst (eds.), From sounds to structures: Beyond the Veil of Maya, 161-92. Berlin: Mouton de Gruyter.

Bodrogligeti, András J.E. 2002. A grammar of Chagatay (Languages of the world, Materials). München: LINCOM.

Csató, Éva Á. \& Lars Johanson. 1998. Turkish. In Lars Johanson \& Éva Á. Csató (eds.), The Turkic languages, chap. 11, 203-35. London: Routledge.

Downing, Laura J. \& Al Mtenje. 2017. The phonology of Chichewa. Oxford: Oxford University Press.

Eckmann, János. 1966. Chagatay manual. Bloomington: Indiana University Press.

Flom, George T. 1934a. Did Old Icelandic have vowel harmony? In Studia Germanica tillägnade Ernst Albin Kock, 45-58. Lund: Gleerup.

Flom, George T. 1934b. Vowel-harmony in Old Norse and Northern Aberdeenshire Scotch. The Journal of English and Germanic Philology 33(2). 178-93.

Frederiksen, Britta Olrik. 2018. Udtale: Gammeldansk. In Ebba Hjorth, Henrik Galberg Jacobsen, Bent Jørgensen, Birgitte Jacobsen, Mette Korvenius Jørgensen \& Laurids Kristian Fahl (eds.), Ord for ord (Dansk sproghistorie vol. 2), chap. 7.2. Aarhus: Aarhus universitetsforlag. 
Gallagher, Gillian. 2010. The perceptual basis of long-distance laryngeal restrictions. Cambridge, Massachusetts: MIT dissertation.

Gowlett, D. F. 1970. Verbal extensions in Mbuunda. African Studies 29(3). 183-200.

Hagland, Jan Ragnar. 1978. A note on Old Norwegian vowel harmony. Nordic Journal of Linguistics 1(2). 141-147.

Harrison, K. David, Mark Dras \& Berk Kapicioglu. 2006. Agent-based modeling of the evolution of vowel harmony. In M. Hirotani (ed.), Proceedings of the Northeast Linguistic Society, vol. 32, 217-36.

Harrison, K. David, Emily Thomford \& Michael O'Keefe. 2004. The vowel harmony calculator. Online: http: //www . swarthmore.edu/SocSci / harmony/public_html/.

Hødnebø, Finn. 1977. Trykk-vokalharmoni-vokalbalanse. In Einar G. Pétursson \& Jónas Kristjánsson (eds.), Sjötíu ritgerðir helgaðar Jakobi Benediktssyni. 20 júli 1977, 375-83. Reykjavík: Stofnun Árna Magnússonar.

Holthausen, Ferdinand. 1948. Vergleichendes und etymologisches Wörterbuch des Altwestnordischen: Altnorwegisch-isländischen. Göttingen: Vandenhoeck \& Ruprecht.

Hreinn Benediktsson. 1964. Old Norse short $e$ : One phoneme or two? Arkiv för nordisk filologi 79. 63-104.

Imer, Lisbeth M. 2017. Peasants and prayers: The inscriptions of Norse Greenland (Publications from the National Museum: Studies in Archaeology and History vol. 25). Odense: University Press of Southern Denmark.

Janhunen, Juha. 1982. On the structure of Proto-Uralic. Finnisch-Ugrische Forschungen 44. 23-42.

Kavitskaya, Darya. 2013. Segmental inventory and the evolution of harmony in Crimean Tatar. Turkic Languages 17. 86-114.

Kiparsky, Paul \& Karl Pajusalu. 2006. Towards a typology of disharmony. The Linguistic Review 20(2-4). 217-41.

Kock, Axel. 1882. Studier öfver fornsvensk ljudlära I. Lund: C. W. K. Gleerups förlag.

Krueger, John Richard. 1962. Yakut manual. Bloomington, Indiana: Indiana University Press.

Leiwo, Matti, Pirjo Kulju \& Katsura Aoyama. 2002. The acquisiton of Finnish vowel harmony. In Anu Airola, Antti Arppe, Orvokki Heinämäki, Matti Miestamo, Kaius Sinnemäki, Urho Määttä, Jussi Niemi, Kari Pitkänen \& Mickael Suominen (eds.), A man of measure: Festschrift in honour of Fred Karlsson, 149-61. Special supplement 
to the SKY Journal of Linguistics 19. The Linguistic Association of Finland.

MacWhinney, Brian. 1978. The acquisition of morphophonology. Monographs of the Society for Research in Child Development 43(1/2). 1123.

Mailhot, Frédéric. 2010. Modelling the acquisition and evolution of vowel harmony. Ottawa, Ontario: Carleton University dissertation.

Mayer, Thomas \& Christian Rohrdantz. 2013. PhonMatrix: Visualizing cooccurrence constraints of sounds. In Proceedings of the 51st Annual Meeting of the Association for Computational Linguistics: Proceedings of the conference system demonstrations, 73-78. Online: http://www . aclweb . org/anthology / P13-4013. Sofia, Bulgaria: Association for Computational Linguistics.

Mayer, Thomas, Christian Rohrdantz, Miriam Butt, Frans Plank \& Daniel A. Keim. 2010. Visualizing vowel harmony. Journal of Linguistic Issues in Language Technology 4(2). 1-33.

McCollum, Adam G. 2015. Labial harmonic shift in Kazakh: Mapping the pathways and motivations for change. In Proceedings of the 41st Annual Meeting of the Berkeley Linguistics Society, 329-52.

McCollum, Adam G. 2019a. Gradience and locality in phonology: Case studies from Turkic vowel harmony. University of California San Diego dissertation.

McCollum, Adam G. 2019b. Gradient morphophonology: Evidence from Uyghur vowel harmony. In Katherine Hout, Anna Mai, Adam G. McCollum, Sharon Rose \& Matthew Zaslansky (eds.), Proceedings of the 2018 Annual Meeting on Phonology. Linguistic Society of America.

McCollum, Adam G. 2020. On how and why vowel harmony decays. Forthcoming. To appear in Oxford handbook of vowel harmony.

McCollum, Adam G. \& Darya Kavitskaya. 2018. Non-iterative vowel harmony in Crimean Tatar. In William G. Bennet, Lindsay Hracs \& Dennis Ryan Storoshenko (eds.), Proceedings of WCCFL 35, 259-68. Sommerville: Cascadilla Proceedings Project.

Myrvoll, Klaus Johan. 2014. Fråværet av vokalharmoni i gamalnorsk etter stutt /æ/ og /Q/. Arkiv för nordisk filologi 129. 5-19.

Nevins, Andrew. 2010. Locality in vowel harmony. Cambridge, MA: MIT Press.

Paulsen, Robert Kristof. 2017. The emRoon referential system. Online: http://www . emroon.no/info/the-emroon-referential-system. pdf.

Poppe, Nikolai. 1960. Vergleichende Grammatik der altaischen Sprachen (Porta linguarum orientalium). Wiesbaden: Otta Harrassowitz. 
Sandstedt, Jade J. 2017. Transparency and blocking in Old Norwegian height harmony. Transactions of the Philological Society 115(3). 395417.

Sandstedt, Jade J. 2018. Feature specifications and contrast in vowel harmony: The orthography and phonology of Old Norwegian height harmony. University of Edinburgh dissertation.

Seip, Didrik Arup. 1955. Norsk språkhistorie til omkring 1370. 2nd edn. Oslo: Aschehoug.

Sjoberg, Andrée F. 1963. Uzbek structural grammar. Bloomington, Indiana: Indiana University Press.

Suomi, Kari. 1983. Palatal harmony: A perceptually motivated phenomenon? Nordic Journal of Linguistics 6(1). 1-35.

van der Hulst, Harry. 2018. Asymmetries in vowel harmony: A representational account. Oxford: Oxford University Press.

Vaux, Bert. 2009. [ATR] and [back] harmony in the Altaic languages. In Sergei Tatevosov (ed.), Investigations into formal Altaic linguistics: Proceedings of WAFL3, 50-67. Moscow: MAKS-Press.

Walker, Rachel. 2005. Weak triggers in vowel harmony. Natural Language \& Linguistic Theory 23(4). 917-89.

Yul-Ifode, Shirley. 2003. Vowel harmony and vowel merger in Agoi. Studies in African Linguistics 32(1). 1-16.

Zaiceva, Maria Ivanovna. 1981. Grammatika vepsskogo yazyka: Fonetika $i$ morfologiya. Leningrad: Nauka. 